\title{
Comparação de informações sobre saúde das populações brasileira e norte-americana baseada em dados da PNAD/98 e NHIS/96
}

\author{
Comparison of health information from \\ Brazil PNAD/98 and USA NHIS/96
}

Kaizô Iwakami Beltrão 1

Sonoê Sugahara 2

\footnotetext{
1 Escola Nacional de Ciências Estatísticas/IBGE. Rua André Cavalcanti 106, 20231-050 Rio de Janeiro RJ. kaizo@ibge.gov.br 2 Instituto de Economia da Universidade Federal do Rio de Janeiro.
}

\begin{abstract}
This paper compares reported health status for Brazilians and Americans, further disaggregated by age groups, sex and race. It also deals with reported morbidity for some selected conditions, namely: arthritis and rheumatism, diabetes, bronchitis and asthma, high blood pressure (hypertension) and heart conditions. Data referring to the Brazilian population comes from a special health questionnaire from PNAD/1998, a household survey conducted annually by IBGE. American data comes from NHIS/1996, also a household survey, but conducted by the Bureau of the Census for the National Center for Health Statistics. Generally speaking, with respect the reported health status, women declare themselves in worse condition and Americans declare themselves better off. Regarding morbidity, there is no overall pattern and differences found among race or sex in a given country is not reproduced in the other.
\end{abstract}

Key words Health condition, Self-reported morbidity, Racial/gender differentials in selfreported morbidity, Comparison of USA/Brazil health conditions
Resumo Neste trabalho comparam-se informações sobre o estado de saúde geral referido das populações brasileira e norte-americana, desagregado por grupo etário, sexo e raça/cor. São comparadas, também desagregadas da mesma forma, taxas de prevalência de morbidades selecionadas, a saber: artrite/reumatismo, diabetes, bronquite/asma, hipertensão e doenças do coração. Os dados concernentes à população brasileira são oriundos do suplemento saúde da PNAD/1998, e os relativos à norte-americana, da NHIS/1996. Em linhas gerais, com respeito ao estado de saúde referido, as mulheres se declaram em pior estado em ambos os países, e os brasileiros se declaram em pior situação. Com respeito à morbidade, não há comportamento comum, e padrões de diferença raça/cor e sexo, via de regra, não se reproduzem igualmente para os dois países.

Palavras-chave Morbidade referida, Diferenciais por sexo/raça de morbidade referida, Condições de saúde, Comparações Brasil/EUA de condições de saúde 


\section{Introdução}

A PNAD/1998 levantou, em seu suplemento, um rol bem abrangente de quesitos ligados ao estado de saúde da população brasileira, bem como de cobertura da população por planos privados de seguro-saúde, acesso a serviços e gastos pessoais com saúde. Mais recentemente, ainda que as definições de saúde tenham privilegiado a idéia do bem-estar do indivíduo e não mais da ausência de morbidade, eram poucas as pesquisas nacionais que levavam isto em consideração. Os suplementos sobre saúde das PNADs dos anos de 1986 e 1988 não foram tão abrangentes quanto a PNAD/1998, ainda que sejam também realizadas com amostras em nível nacional. A Pesquisa de Padrão de Vida (PPV) pesquisou também alguns elementos referentes à saúde, mas não tem representatividade nacional. A Demographic Health Survey (DHS), a Pesquisa Nacional de Demografia e Saúde (PNDS), e a Pesquisa de Orçamento Familiar (POF) estão na mesma situação. Com respeito à saúde individual, a pesquisa da PNAD/1998, além do estado geral de saúde (informação subjetiva), fornece informações sobre doenças crônicas e as dificuldades para desempenhar determinadas tarefas rotineiras. Um uso possível dessas informações consiste em cotejá-las com pesquisas semelhantes de outros países, que permitem, por um lado, a validação das respostas encontradas e, por outro, a comparação propriamente dita das situações de outros países ou regiões.

Neste estudo vamos trabalhar com as informações da PNAD e da NHIS/1996. A NHIS (National Health Interview Survey) é uma pesquisa anual realizada pelo US Bureau of the Census para o National Center of Health Statistics. As informações são coletadas em uma pesquisa domiciliar não institucionalizada sobre uma variedade de tópicos relacionados à saúde da população civil. Primeiramente, analisamos o quesito referente ao estado geral de saúde, desagregando-o por sexo, raça e grupo etário qüinqüenal. Num segundo momento, consideramos também a morbidade referida para cinco condições específicas: artrite e reumatismo, diabetes, bronquite ou asma, hipertensão e doenças do coração. Para estas, levamos em conta, também, uma desagregação por sexo, raça e grupo etário.

Quanto ao quesito raça, ainda que os dados da PNAD e da NHIS considerem uma gama variada de cores/raças (no Brasil) e grupos étnicos (nos EUA), vamos nos ater, por questões de comparabilidade, aos grupos "brancos" e "ne- gros", incluindo neste último os indivíduos que se declaram "pretos" e "pardos". A classe, "negros", criada a partir da junção de "pretos" e "pardos" tem mais afinidade com o conceito "black" utilizado nos EUA e na linha dos afro-descendentes, como reivindicam os movimentos negros. Costa (1974), Hasenbalg (1979), Hasenbalg \& Silva (1991) e Oliveira (2001) apresentam uma discussão sobre o conceito de raça/cor nas pesquisas brasileiras.

A PNAD é uma pesquisa domiciliar com uma estrutura amostral complexa (estratificada e em três estágios), realizada anualmente em setembro. Em 1998 contabilizou 344.975 indivíduos num universo estimado de 158 milhões. $\mathrm{O}$ NHIS também é uma pesquisa domiciliar com estrutura amostral complexa (estratificada e em vários estágios). É realizada semanalmente ao longo do ano, mas os dados são disponibilizados para o ano como um todo. Em 1996, a amostra foi composta por 63.402 indivíduos num universo de 264 milhões. Como se pode ver, a amostra da PNAD apresenta uma fração amostral média maior do que a da NHIS.

\section{Condições gerais de saúde referida}

\section{Conceitos}

Mais recentemente, ainda que as definições de saúde tenham privilegiado a idéia do bemestar dos indivíduos e não mais da ausência de morbidades, eram poucas as pesquisas nacionais que levavam isto em consideração. Os quesitos da PNAD e da NHIS são na forma de autoavaliação (ou avaliação por terceiros no domicílio). Apesar de suas limitações, a auto-avaliação tem sido considerada um importante preditor das condições de saúde do indivíduo (Ries, 1990) e tem sido largamente utilizada como um primeiro indicador. Deb e Triveti (1997) utilizam essa informação como a principal co-variável na regressão para estudar demanda de serviços de saúde por parte dos idosos americanos.

O quesito na PNAD é "De um modo geral... considera o seu próprio estado de saúde" (no pontilhado deve-se colocar o nome do indivíduo pesquisado se não for ele o respondente ou ignorar os espaços, caso contrário), e as respostas possíveis são: 1) muito bom (MB); 2) bom (B); 3) regular (RG);4) ruim (R); e 5) muito ruim (MR). Por motivos operacionais, o banco de dados inclui 9, ignorado, como uma das respostas. Nos EUA, a NHIS/1996 faz aos indivíduos a 
seguinte pergunta sobre seu estado de saúde: "Would you say... health in general is excellent, very good, good, fair or poor?" As respostas possíveis são: 1) excellent $(\mathrm{E})$;2) very good $(\mathrm{VG}) ; 3)$ good (G); 4) fair (F); 5) poor (P); e 6) unknown. Stricto sensu, diríamos que a escala brasileira é mais pessimista ou considera uma realidade pior, já que inclui um "muito ruim", não contemplado na escala americana que, por sua vez, contém a categoria "excellent", não contemplada na brasileira. Para a comparação estrita, esbarramos em dois enfoques básicos, o primeiro dos quais é a utilização da definição pura das palavras. Admitimos, porém, que uma simples tradução não seria suficiente para explicar as nuances dos conceitos. Numa tentativa de aproximação, utilizando a mera tradução, o primeiro nível da escala brasileira seria equivalente ao segundo da escala americana. $\mathrm{O}$ outro enfoque tem a ver com o fator psicológico de serem apresentadas cinco respostas qualitativas ordenadas. Existe uma tendência de se considerar a classe central uma situação igualmente distante dos extremos (pior e melhor). Neste caso, a equivalência seria de cada categoria brasileira com a sua contraparte americana, em ordem. Dessa forma, MB seria equivalente a EX, B a VG, e assim por diante.

Cumpre notar que, apesar de a pergunta permitir que o próprio indivíduo declare o seu estado geral de saúde, nem sempre isso acontece.

\section{Comparações das condições referidas no Brasil e nos Estados Unidos da América por sexo e grupo etário}

A figura 1 apresenta, para os homens e para as mulheres, as proporções cumulativas do estado de saúde referido pelos brasileiros. No eixo da esquerda, temos a situação cumulativa do melhor para o pior e, no eixo da direita, a ordem inversa, do pior para o melhor. Por exemplo, podemos ver que a proporção de indivíduos brasileiros do sexo masculino que se declaram de saúde $\mathrm{B}$ ou $\mathrm{MB}$, como função da idade, cresce até o terceiro grupo etário e depois decresce. Podemos ver também que as proporções de indivíduos que se declaram de saúde $\mathrm{R}$ ou MR são crescentes com a idade. Ambos os sexos apresentam, basicamente, perfis semelhantes, ainda que com níveis diferentes.

$\mathrm{Na}$ mesma figura podemos comparar, entre os sexos, o estado de saúde da população brasileira. Nota-se que a situação referida pelas mulheres é sempre pior do que a dos homens. Para uma dada categoria, as curvas correspondentes às mulheres estão sempre abaixo das dos homens, a não ser, possivelmente, para as idades extremas (os mais jovens e os mais velhos).

Para uma melhor avaliação da situação relativa de homens e mulheres, a figura 2 apresenta, respectivamente para cada situação cumulativa

Figura 1

Condição de saúde referida - Brasil.

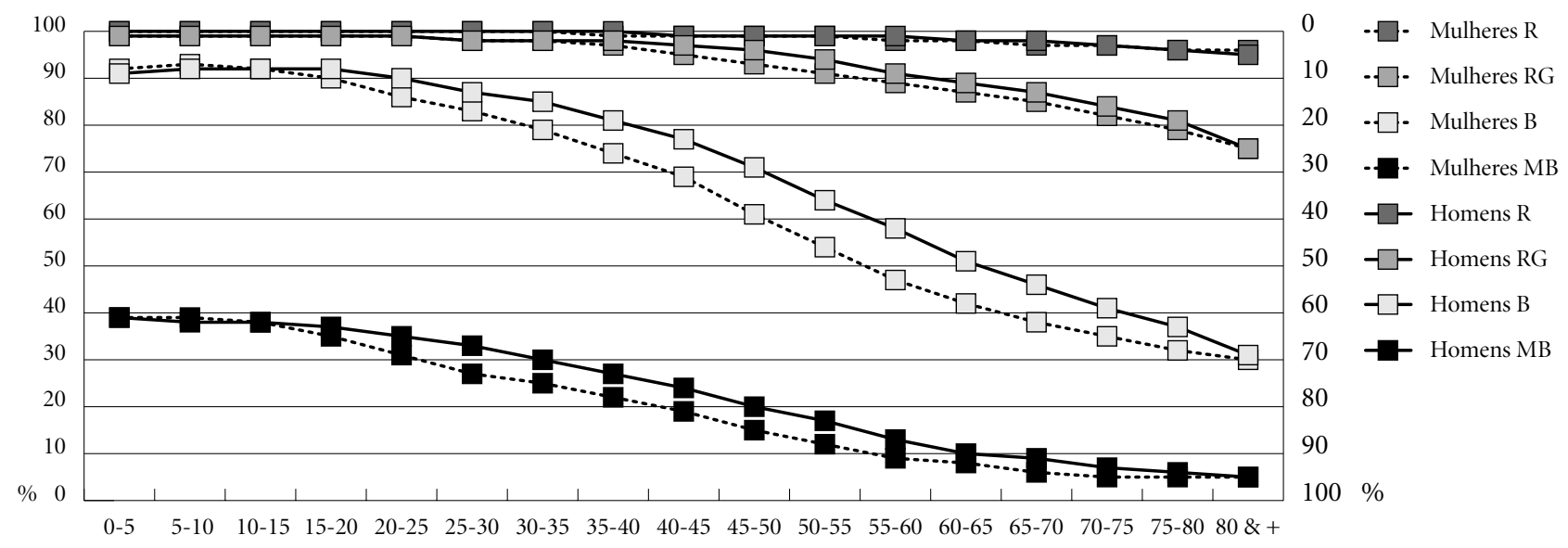


Figura 2

Razão de sexos da condição de saúde referida - Brasil.

Figura 2a

Ascendente

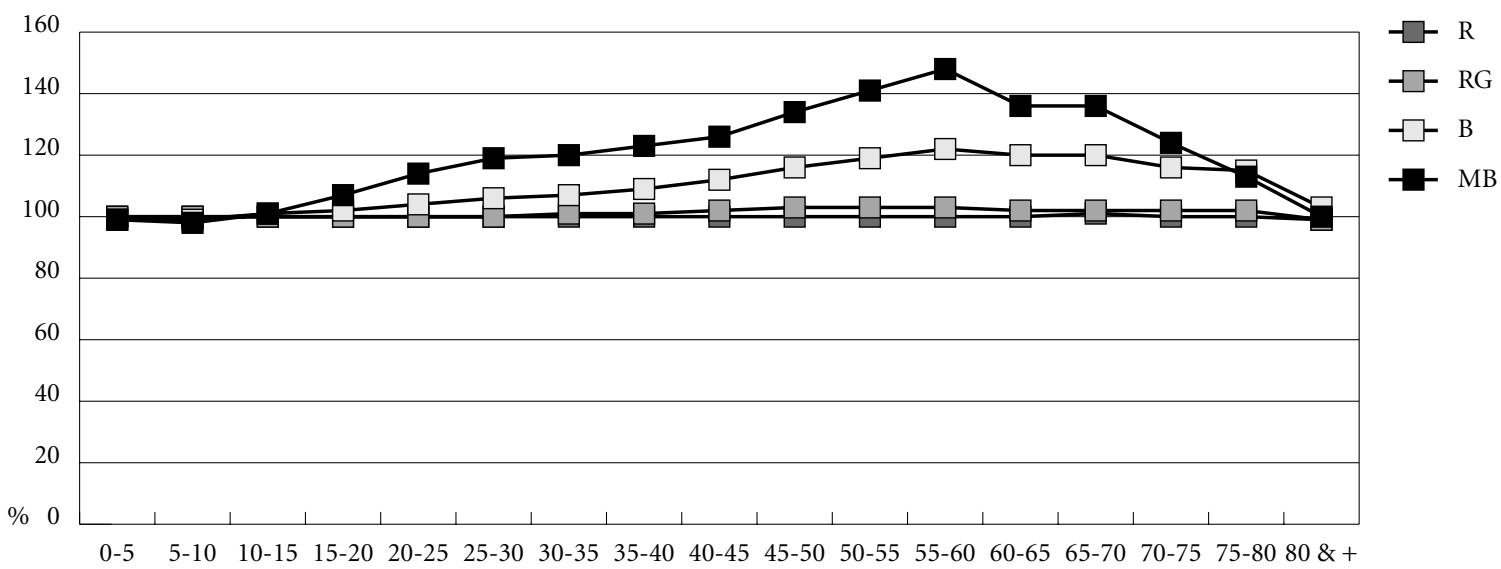

Figura $2 b$

Descendente

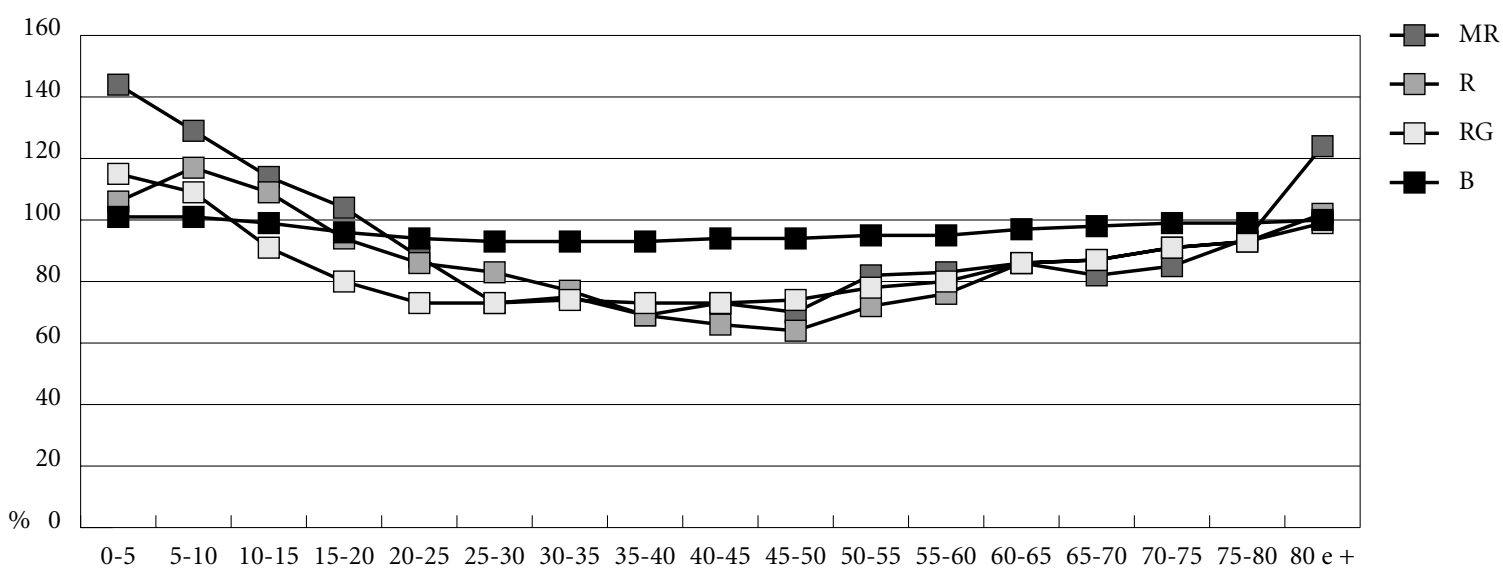


ascendente e descendente, a razão de sexos da população brasileira. Nessa figura observamos que na população de 55 a 60 anos, proporcionalmente, $48 \%$ a mais de homens do que de mulheres se declaram em situação MB. Nesse mesmo grupo etário, $22 \%$ a mais de homens se declaram em situação B ou MB. Em linhas gerais, podemos dizer que os homens se declaram em melhor condição de saúde do que as mulheres. A comparação na ordem descendente conta uma história um pouco diferente, pelo menos nos grupos etários extremos, isto é, aqueles muito jovens ou muito idosos. Por exemplo, para o grupo etário de 15 a 20 anos, temos 14\% a mais de homens que se declaram com saúde MR e 9\%, MR ou R. Nas idades centrais, também os homens declaram ter um melhor estado de saúde do que as mulheres.

A figura 3 e a figura 4 apresentam informações equivalentes à figura $1 \mathrm{e}$ à figura 2 , com a ressalva de que dizem respeito aos EUA. A forma dos gráficos referentes a este país é bem semelhante à sua contraparte brasileira. As maiores diferenças ocorrem nas razões de sexo ascendentes para os dois últimos grupos idosos e nas descendentes para os primeiros grupos nas idades jovens. As razões de sexo para as duas melhores categorias (ver Figura 4) não são unimodais como para o Brasil, mas apresentam um platô com uma diferença constante para os gru- pos etários entre 20 e 70 anos de idade: em torno de $20 \%$ a mais de homens para a categoria EX e $10 \%$ para as categorias EX e VG. Para a população acima de 75 anos de idade (dois últimos grupos etários), no Brasil os homens registram sempre melhores condições para todos os níveis cumulativos do melhor para o pior. Nos EUA, acontece a situação inversa.

A figura 5 apresenta uma comparação do estado de saúde registrado nos EUA e no Brasil, primeiro para homens e depois para mulheres. Podemos notar que o comportamento é semelhante para ambos os sexos. As únicas linhas que se cruzam, tanto para o sexo feminino quanto para o masculino, são a B do Brasil e a VG dos EUA. Qualquer que seja o enfoque de comparação para as categorias de respostas, no extremo melhor da escala o indivíduo americano declara-se em melhor situação. A primeira categoria americana, EX, apresenta uma taxa de respostas superior à primeira brasileira, MB. No extremo pior, a ordenação é $\mathrm{MR}, \mathrm{P}, \mathrm{R}, \mathrm{F}, \mathrm{RG}$.

Seria interessante uma comparação das inclinações das diferentes curvas como função da idade. Taxas de prevalência, como todas as outras probabilidades, são números limitados entre 0 e 1 , o que, de alguma forma, limita semelhante idéia. Sendo assim, calculamos os logitos das taxas, que são valores não-limitados e calculamos as inclinações médias das curvas cor-

Figura 3

Condição de saúde referida - EUA.

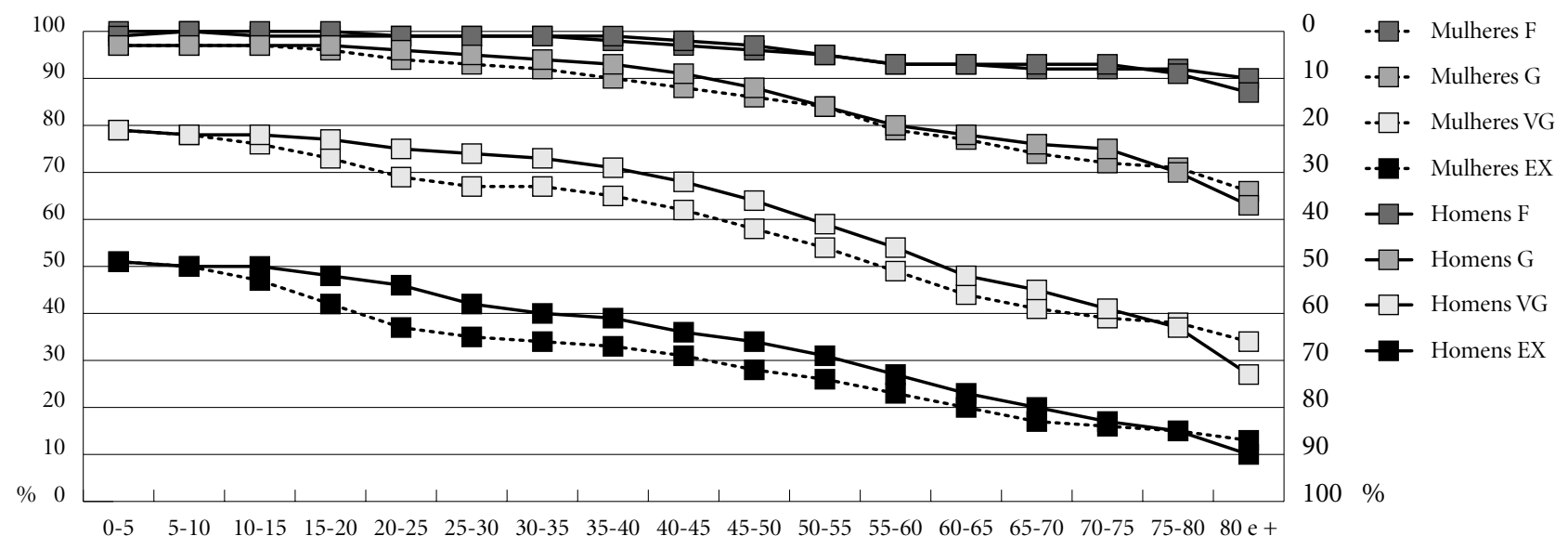

Fonte: NHIS 1996 
Figura 4

Razão de sexos da condição de saúde referida - EUA.

Figura 4a

Ascendente

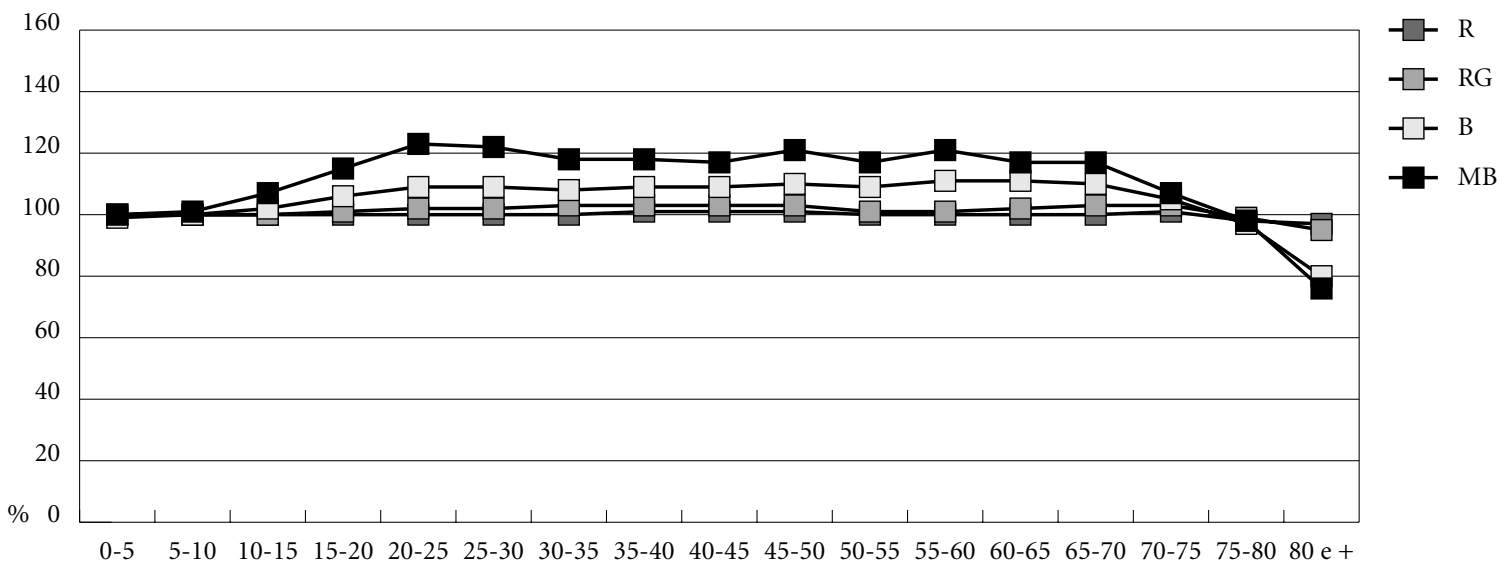

\section{Figura $4 b$}

Descendente

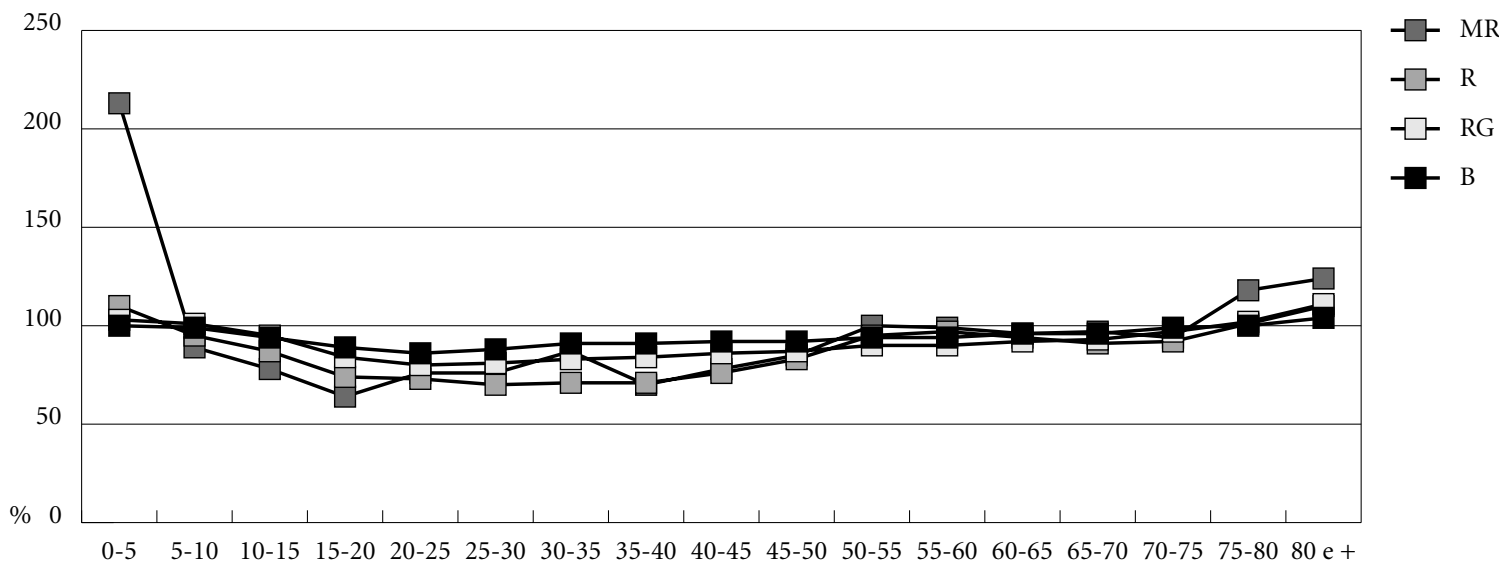


Figura 5

Condição de saúde referida - Brasil e EUA.

Figura 5a

Homens

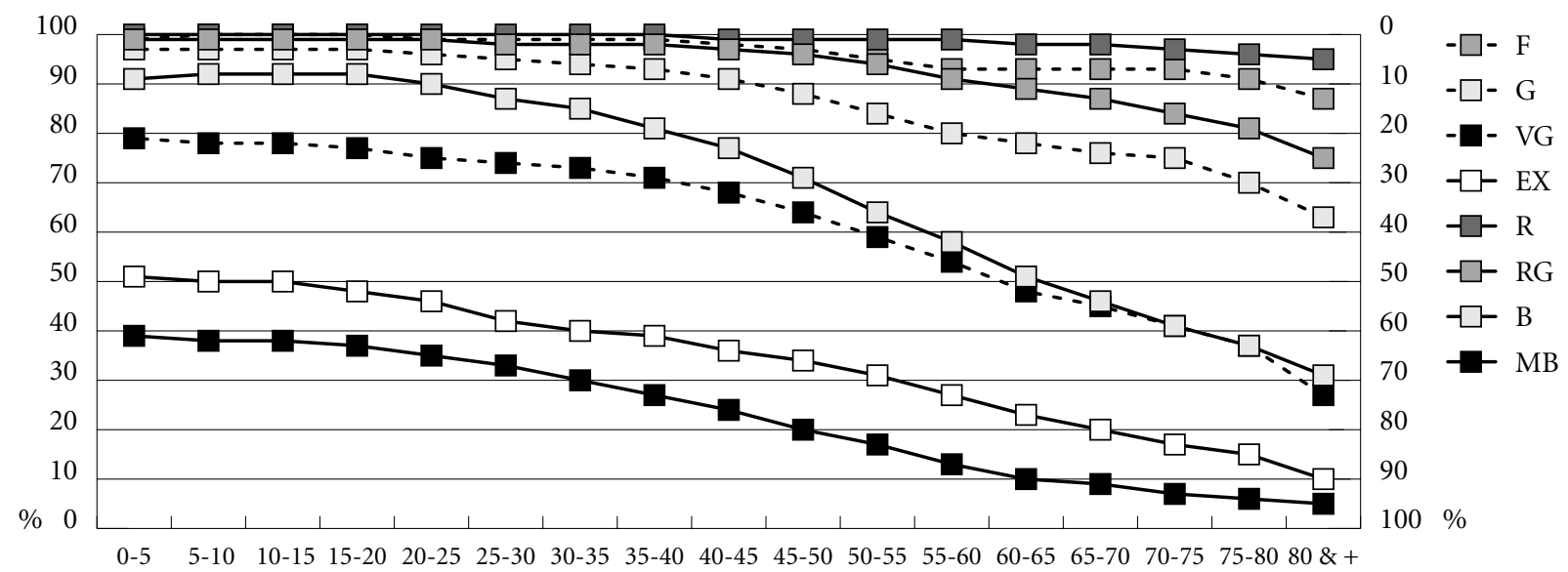

Figura 5b

Mulheres

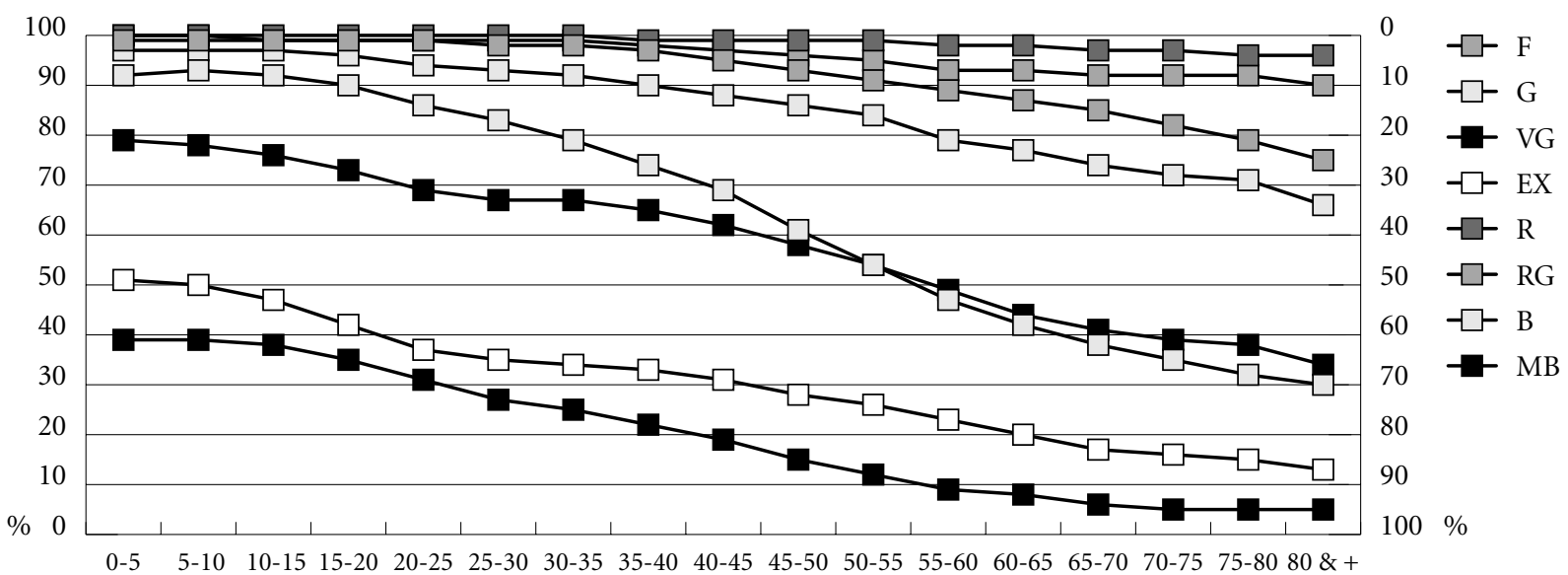


respondentes. O logito da taxa é definido como o logaritmo da chance correspondente, ou seja

$\operatorname{logit}(p)=\operatorname{In} \frac{p}{1-p}$.

Para os EUA, os logitos das taxas se apresentam quase lineares nos grupos etários centrais, ao mesmo tempo em que se mostram menos inclinadas. Para o Brasil, as funções parecem paralelas entre os sexos.

A figura 6 apresenta as taxas de decréscimo do logito da condição de saúde declarada pelas populações brasileira e americana, desagregadas por sexo. Para o cálculo das taxas, foram utilizados os grupos etários entre 15 e 75 anos de idade. Dado que todas as taxas se apresentam negativas, quanto maior a taxa, em valor absoluto, mais rápido é o declínio. Em geral, as taxas de declínio na condição de saúde se mostram mais acentuadas para o Brasil. Podemos observar que, nos EUA, quanto pior a condição, maior a taxa. No Brasil, a última categoria se apresenta com um decréscimo menos acentuado que a anterior. As diferenças entre as taxas brasileiras de homens e mulheres são pequenas e estas últimas, com exceção da primeira melhor categoria, apresentam taxas ligeiramente menores, novamente em módulo. Nos EUA, o hiato entre os sexos é bem maior que no Brasil.

Podemos ainda apreciar na figura 6 as mesmas taxas desagregadas por sexo e raça. Novamente, as taxas brasileiras se apresentam muito menos dispersas que as dos EUA, pois as taxas americanas são decrescentes com a piora da situação declarada, ao passo que a situação brasileira apresenta a retomada na última categoria $\mathrm{e}$ as mulheres apresentam taxas menores do que as masculinas.

\section{Comparações das condições referidas no Brasil e nos Estados Unidos da América por sexo e grupo etário - raça branca}

A figura 7 apresenta a comparação entre homens e mulheres brancos brasileiros. A situação é melhor para este grupo do que para a população como um todo: existe, para todas as categorias, uma maior proporção de indivíduos que se declaram em condição positiva. O hiato entre os sexos é basicamente o mesmo para a população como um todo: para quase todas as idades, os homens se declaram em melhor estado de saúde, mas, nas idades extremas, a melhor situação é feminina.
Ainda na mesma figura encontra-se a comparação entre homens e mulheres brancos americanos. Nota-se, também uma melhor situação da população branca deste país em relação aos indivíduos com mais de 80 anos. O hiato entre os sexos está na mesma direção que para a população como um todo, com exceção da categoria $\mathrm{P}$ : a partir de 55 anos de idade, existem proporcionalmente mais homens do que mulheres que se declaram nesta situação.

A figura 8 apresenta uma comparação do estado de saúde registrado pela população branca em ambos os países, primeiro para homens e depois para mulheres. O padrão é em tudo paralelo ao encontrado para as populações como um todo, apenas com menores diferenças nas situações piores: B e VG se cruzam, o indivíduo americano declara-se em melhor situação, EX apresenta uma taxa de respostas superior à da $\mathrm{MB} \mathrm{e}$, no extremo pior, a ordenação é MR, P, R, F, RG.

\section{Comparações das condições referidas no Brasil e nos Estados Unidos da América por sexo e grupo etário - raça negra}

A figura 9 apresenta a comparação entre sexos para os negros brasileiros. Ainda que, em linhas gerais, o comportamento seja semelhante ao encontrado para a população como um todo (ver Figura 3) e também para a população branca (ver Figura 7), existe uma discrepância nas taxas cumulativas até as categorias centrais. Para a população negra, as mulheres nas categorias B, ou melhor, RG e melhor, não estão em maior proporção do que os homens.

Nos EUA, a população negra feminina apresenta um comportamento diferente do que se observa entre as demais. Para todas as outras populações consideradas até agora, a partir da idade adulta notava-se uma deterioração do estado de saúde da população sobrevivente, isto é, uma retração da proporção de população que se declarava nas melhores categorias, concomitante com uma expansão da que se declarava na situação oposta. No entanto, entre as mulheres negras americanas, a partir de 60-65 anos, ocorre o fenômeno inverso: uma diminuição da população nas categorias correspondentes às piores condições de saúde e um aumento da que se declara EX, pelo menos VG e pelo menos G. Este fato poderia ser explicado por uma mortalidade muito maior entre a população em piores condições de saúde.

Para os homens negros (Figura 10) não existe o cruzamento entre as categorias B e VG. 
Figura 6

Taxas de decréscimo do logito da condição de saúde referida para as categorias cumulativas.

\section{Figura 6a}

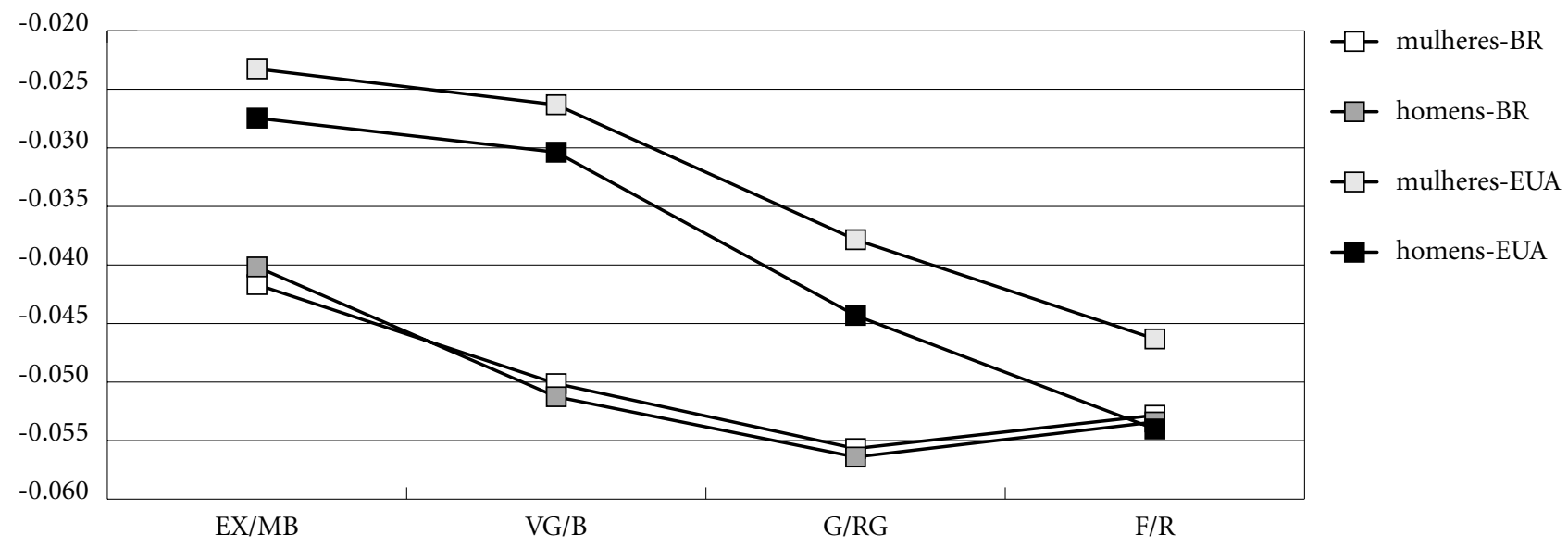

Figura 6b

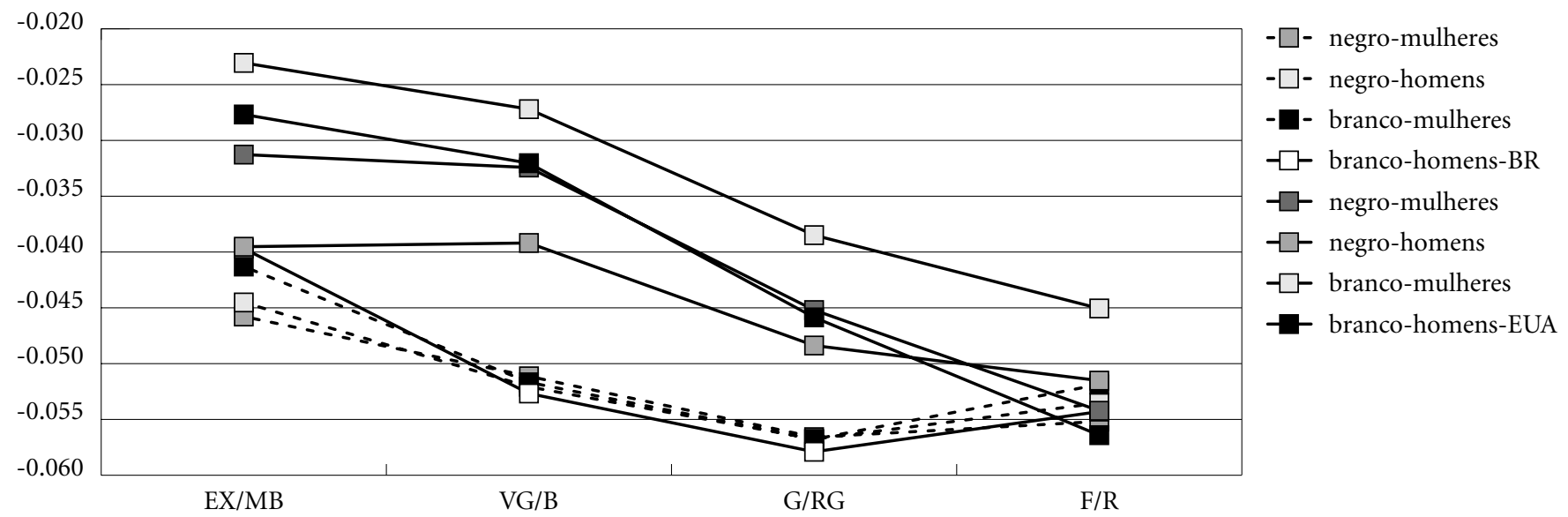

Fonte: PNAD 1998 e NHIS 1996 
Figura 7

Condição de saúde referida.

\section{Figura 7a}

Brancos - Brasil

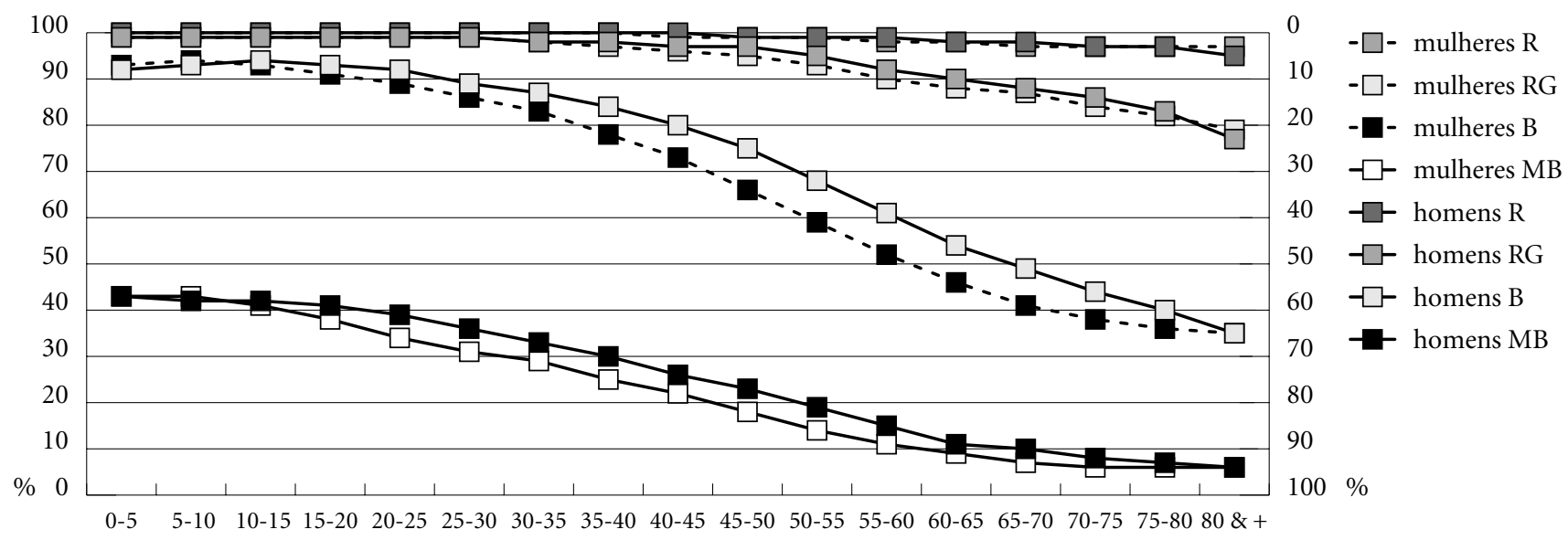

Figura $7 b$

Brancos - EUA

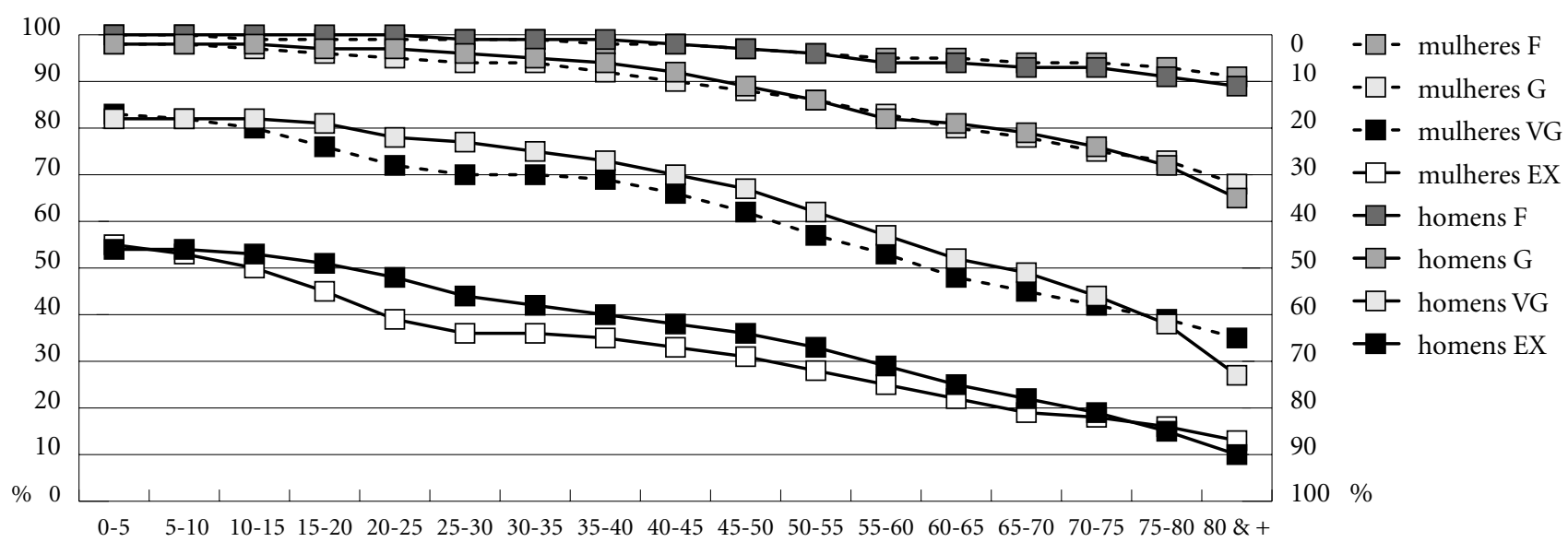


Figura 8

Condição de saúde referida - Brasil e EUA.

Figura 8a

Homens brancos

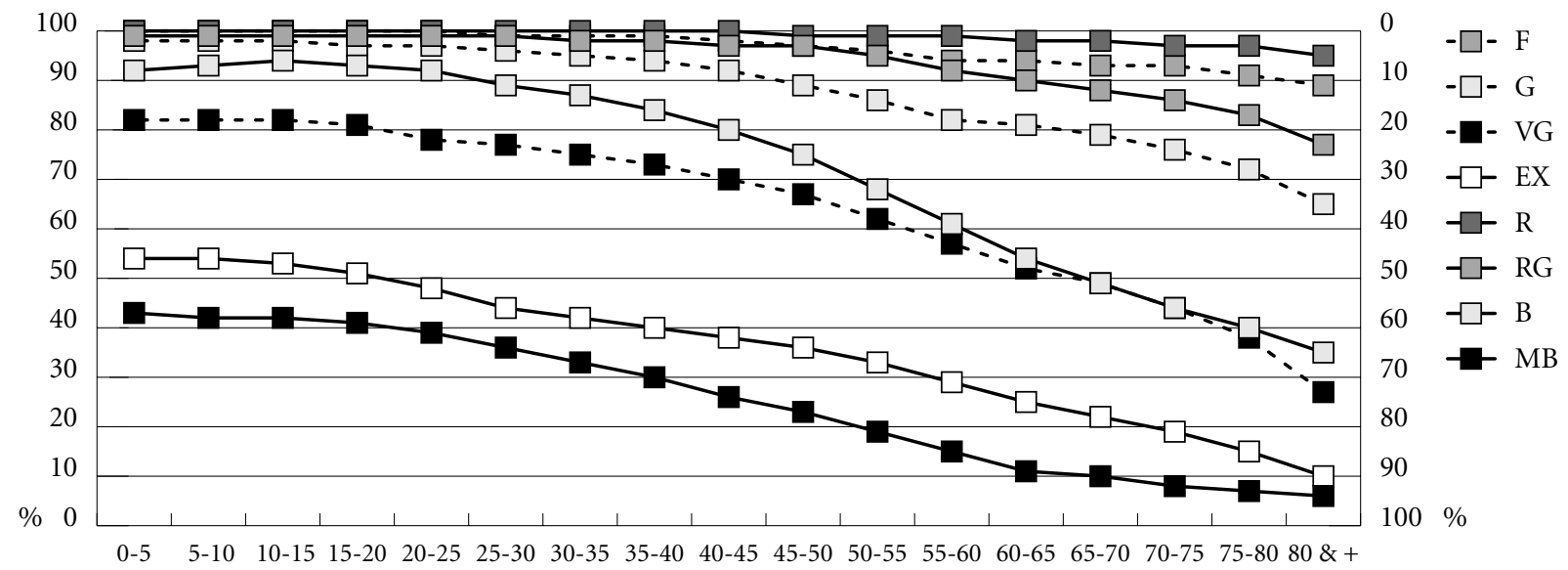

Figura 8b

Mulheres brancas

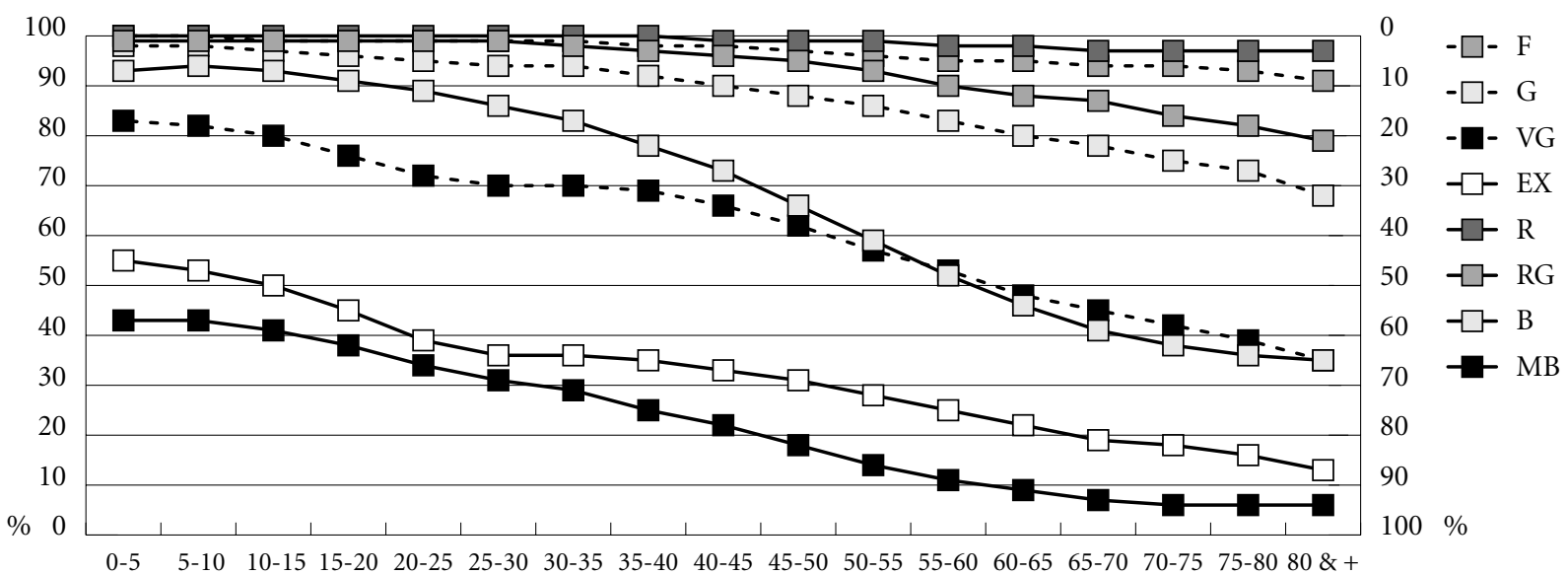

Fonte: PNAD 1998 e NHIS 1996 
Figura 9

Condição de saúde referida.

\section{Figura 9a}

Negros - Brasil

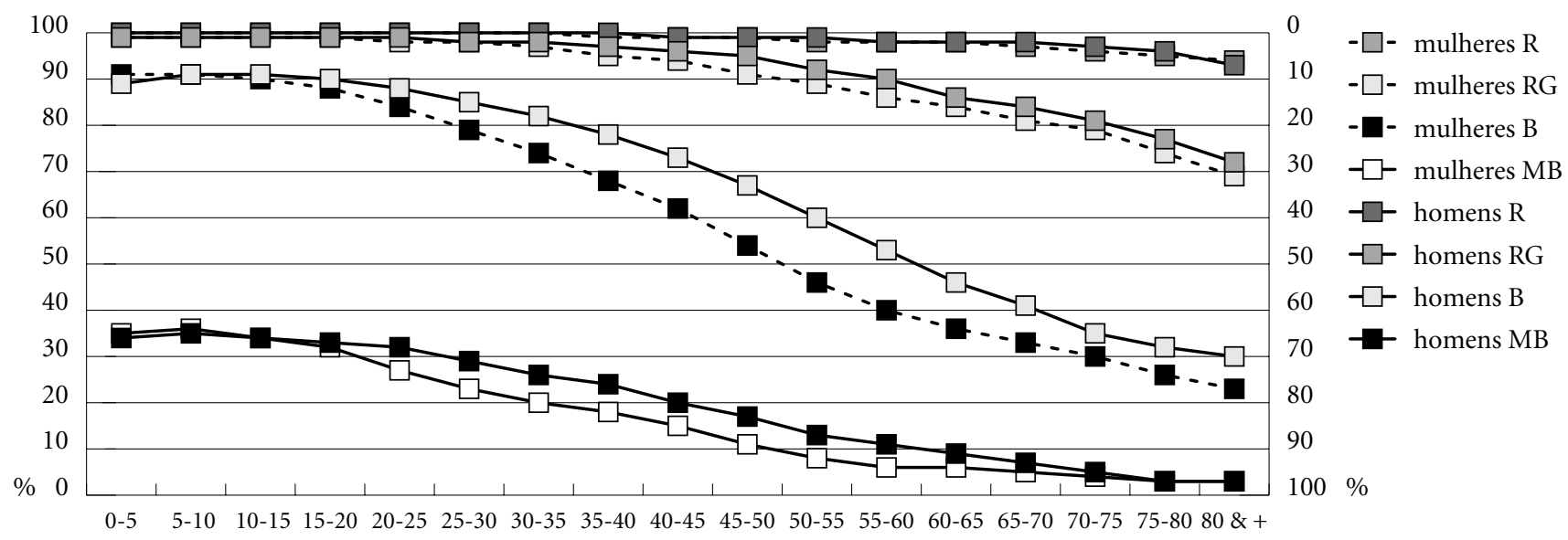

Figura 9b

Negros - EUA

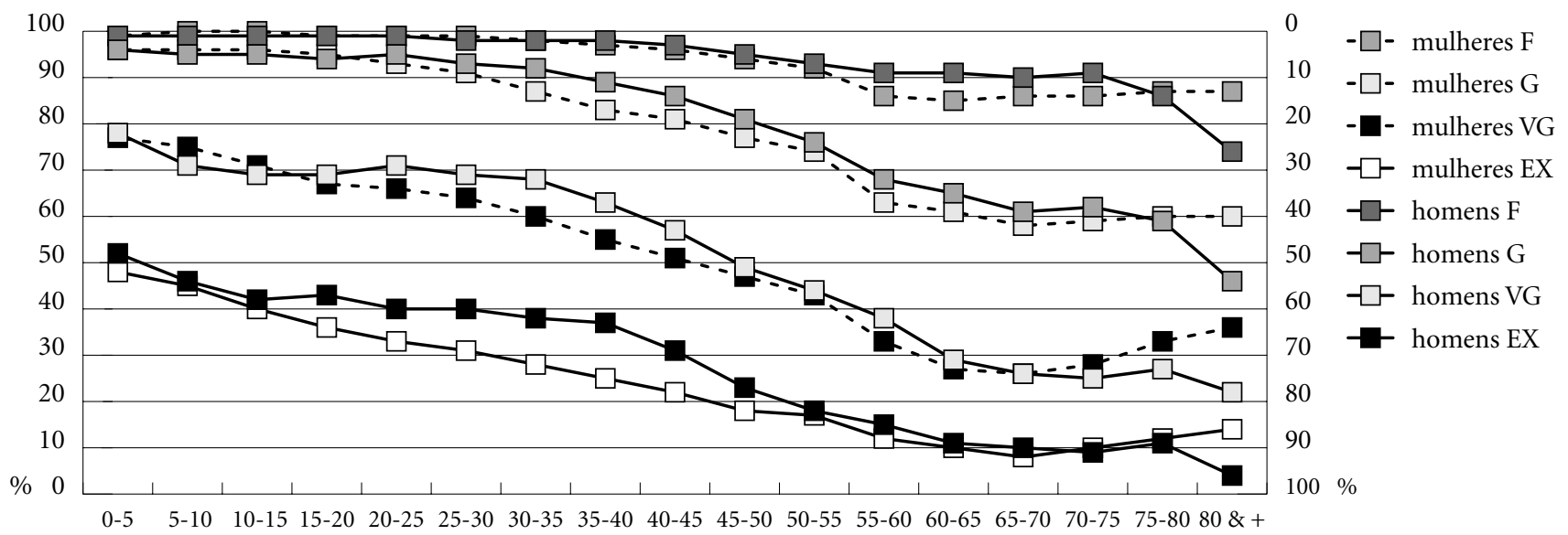


Figura 10

Condição de saúde referida - Brasil e EUA.

Figura 10a

Homesns negros

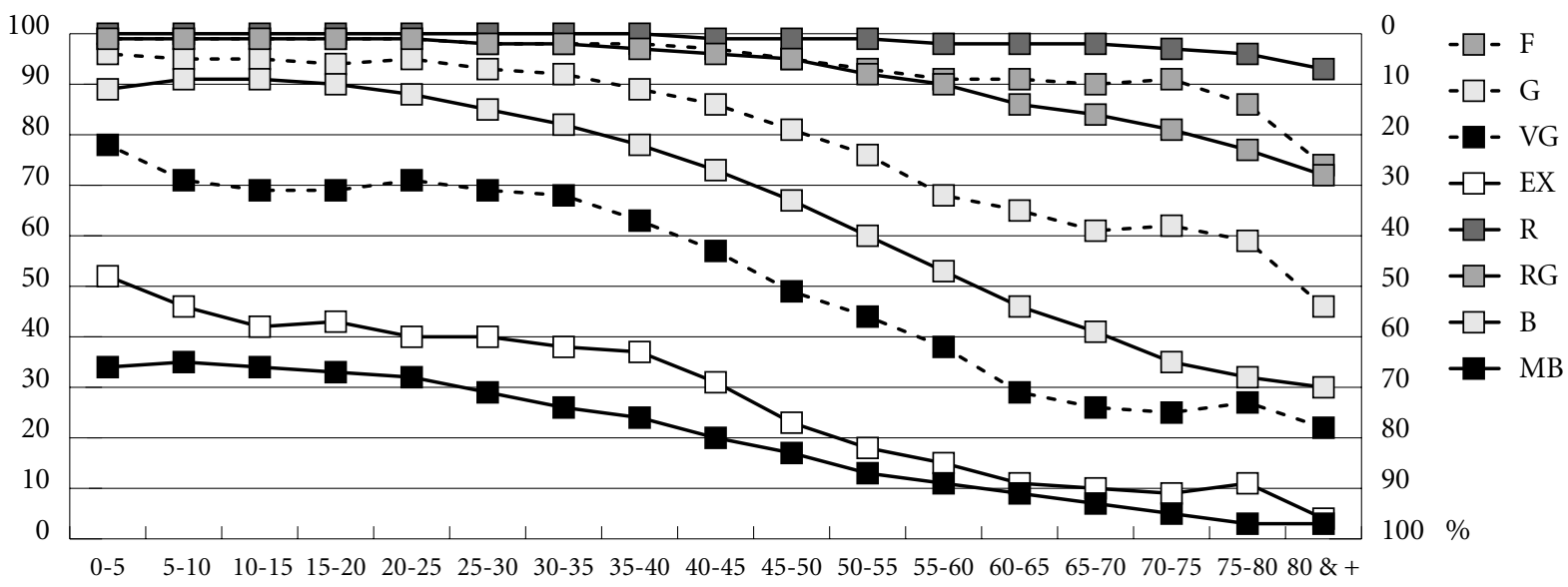

Figura 10b

Mulheres negras

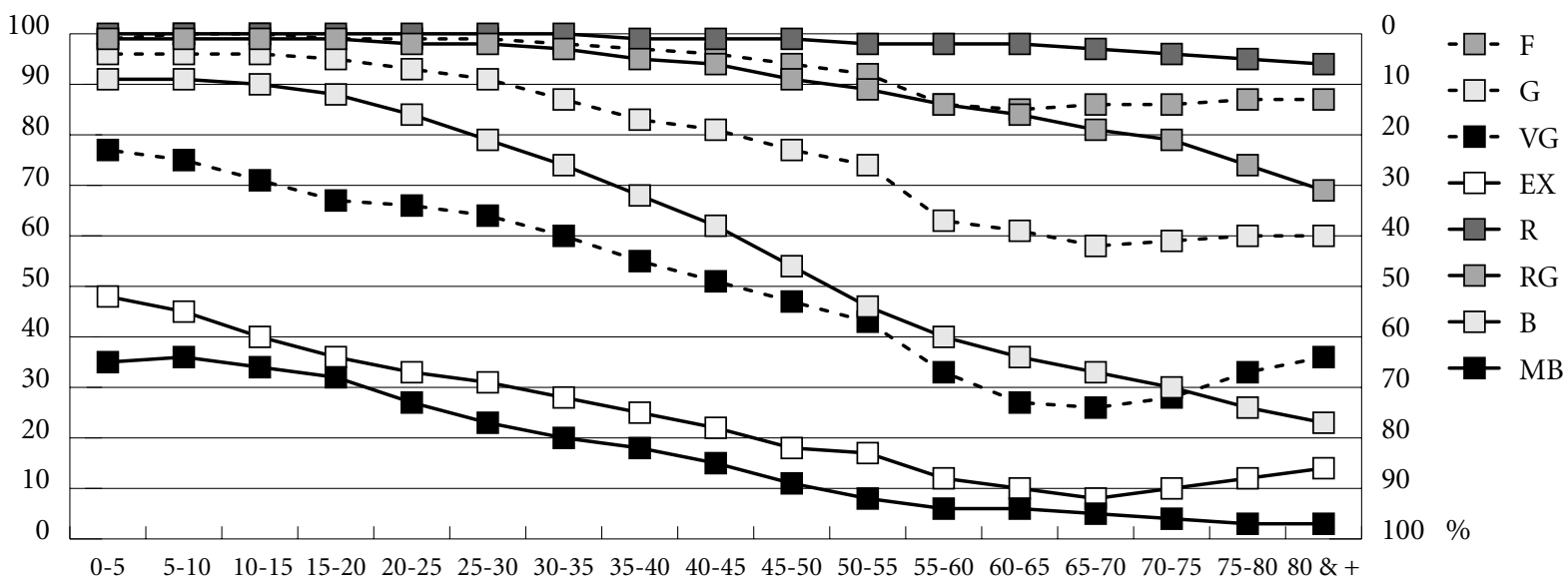


Entre as mulheres, persiste o cruzamento dessas categorias.

\section{Morbidade referida}

\section{Conceitos}

Apresentamos, a seguir as taxas de prevalência referidas, por sexo e raça, de algumas condições de morbidade selecionadas entre a população brasileira: artrite/reumatismo, diabetes, bronquite/asma, hipertensão e doenças do coração. Apresentamos, também, uma comparação entre as taxas de prevalência de morbidade similares entre as populações brasileira e americana.

Como já mencionado, os dados para o Brasil foram extraídos da PNAD, na verdade um suplemento especial sobre saúde que foi conduzido juntamente com a PNAD/1998. Extraímos as variáveis V1310 (artrite ou reumatismo?), V1312 (diabetes?), V1313 (bronquite ou asma?), V1314 (hipertensão?) e V1315 (doenças cardíacas?). As respostas possíveis para cada uma dessas perguntas eram: sim ou não. Alguns indivíduos apresentam ignorados (não preenchido) no quesito. Outras variáveis extraídas se referem a idade, sexo, raça/cor e peso para expansão da amostra. A PNAD cobre não só as áreas urbanas de todos os 26 estados brasileiros, inclusive o DF, mas também as áreas rurais de todos os estados, exceto cinco da região Norte. Os quesitos na PNAD são apresentados ao respondente da seguinte forma: “... tem artrite ou reumatismo?”, “... tem diabetes?”, “... tem bronquite ou asma?” e “... tem hipertensão?” e “... tem doença do coração?” (como já mencionado, no pontilhado deve-se colocar o nome do indivíduo pesquisado se não for ele o respondente ou ignorar os espaços, caso contrário). As respostas são sempre "sim" ou "não".

Para esta seção, também, os dados para os Estados Unidos foram extraídos da NHIS - National Health Interview Survey - de 1996. As variáveis foram obtidas dos conjuntos Person Records e Condition Records. Este último se divide em vários itens, e as informações utilizadas são as classificadas como "chronic condition". Os quesitos da NHIS, com respeito a condições crônicas, são subdivididos em seis listas separadas e cada família na amostra é questionada somente sobre uma das listas. As perguntas são da seguinte forma: "In the last 12 months did anyone in the family have (lista de condições)". Con- sideramos os códigos 101-109 da lista 1 (artrite/reumatismo), código 403 da lista 4 (diabetes), códigos 601-602 da lista 6 (bronquite/asma), código 508 da lista 5 (hipertensão) e códigos 501-507 da lista 5 (doenças do coração).

As taxas de prevalência foram calculadas como uma razão entre o número de pessoas de um dado grupo etário, sexo e raça que declara sofrer uma condição de morbidade específica, e todas as pessoas nesse grupo etário, sexo e raça:

i) $P(a, s, r, m)=\frac{p o p(a, s, r, m)}{\operatorname{pop}(a, s, r)}$.

para a taxa de prevalência do grupo etário $a$, sexo $s$, raça $r$ e condição de morbidade $m$;

ii) $P(a, s, ., m)=\frac{\sum_{r} p o p(a, s, r, m)}{\sum_{r} p o p(a, s, r)}$

para a taxa de prevalência do grupo etário $a$, sexo $s$ e condição de morbidade $m$;

Nas fórmulas acima, é a população do grupo etário $a$, sexo $s$, raça $r$, enquanto pop $(a, s, r$, $m$ ) é o subconjunto dessa população que sofre da condição de morbidade $m$. Em tais fórmulas, a ausência do parâmetro indica o somatório sobre todos os grupos. Por exemplo, a ausência do parâmetro $r$ (raça) indica que estamos considerando todas as raças.

Para cada uma das morbidades, serão apresentadas quatro figuras comparando primeiro as morbidades masculinas e femininas nos dois países, seguidos da comparação desagregando por raça/cor. Nos dois últimos, consideramos cada sexo em separado, e a análise é realizada por raça/cor e países.

\section{Comparações das condições referidas no Brasil e nos Estados Unidos da América por sexo, raça e grupo etário - artrite e reumatismo}

Em linhas gerais, as taxas de prevalência de artrite e reumatismo parecem mostrar uma grande discrepância nos níveis entre os dados dos EUA e do Brasil, ainda que todas se apresentem monotônicas crescentes. As taxas brasileiras por sexo são em torno de 50 vezes mais altas do que as americanas (Figura 11). Além disso, nos EUA são as mulheres que apresentam a maior prevalência, enquanto no Brasil são os homens (Figura 12). Não obstante a desagregação por raça/cor, as discrepâncias persistem. A população 
negra brasileira apresenta valores em torno de $10 \%$, já os brasileiros brancos, uma prevalência no nível de $1 \%$. Por sua vez, os americanos, brancos e negros, apresentam taxas crescentes, com valores compreendidos entre $0,0001 \%$ nas primeiras idades e $0,01 \%$ nas idades avançadas. As prevalências para os negros brasileiros se mostram côncavas e para os brancos, convexas. Os valores para os negros americanos são ligeiramente inferiores aos dos brancos. Tanto para os homens, quanto para as mulheres, o padrão das taxas de prevalência de artrite e reumatismo é o mesmo para ambos os sexos, sendo que a diferença entre negros e brancos americanos não é bem caracterizada para as mulheres negras americanas.

\section{Comparações das condições referidas no Brasil e nos Estados Unidos da América por sexo, raça e grupo etário - diabetes}

Em linhas gerais, as taxas de prevalência de diabetes são côncavas e crescentes com a idade. Nos EUA, nota-se uma pequena queda para as idades mais avançadas e um comportamento mais errático nas primeiras idades. Este pode ser fruto do menor tamanho da amostra americana. No Brasil, os homens apresentam taxas de prevalência inferiores às das mulheres para todos os grupos etários considerados. Nos EUA, os homens apresentam taxas maiores nos grupos etários extremos, isto é, mais jovens (menos de 25 anos) e mais velhos (mais de 50 anos). As taxas femininas dos dois países são bem mais parecidas do que as masculinas.

No Brasil, a população negra apresenta taxas inferiores às da população branca nas idades extremas, ou seja, menos de 40 anos e mais de 80. No intervalo intermediário, as diferenças não são estatisticamente significativas. Ao contrário, nos EUA, a população negra apresenta taxas quase sempre maiores do que a população branca. Quando introduzimos a variável sexo, esse padrão se mantém para os homens e mulheres americanos. Entre os homens brasileiros, os negros apresentam taxas inferiores às dos brancos. Entre as mulheres brasileiras, ainda que até os 30 anos as taxas das mulheres negras sejam inferiores às das brancas, a partir dessa idade a posição se reverte, mas não com uma diferença estatisticamente significativa.

\section{Comparações das condições referidas no Brasil e nos Estados Unidos da América por sexo, raça e grupo etário - bronquite/asma}

As taxas de prevalência de bronquite/asma apresentam padrões razoavelmente distintos nos dois países, qualquer que seja a desagregação: sexo, raça/cor ou ambos. As taxas brasileiras são sempre convexas e inferiores às americanas, que, por sua vez, se apresentam como retas sem concavidade, quase horizontais ou com ligeira inclinação. Na desagregação por sexo (Figura 13), os homens apresentam maior prevalência nas primeiras idades, e as mulheres, nas demais. Os homens americanos apresentam uma tendência decrescente, enquanto as mulheres têm o comportamento oposto, isto é, uma curva crescente. Desagregando por raça, vemos que os negros brasileiros apresentam prevalência mais baixa do que a de seus conterrâneos brancos, a não ser para os homens acima de 45 anos de idade. Entre os americanos, o único padrão recorrente é o de maiores taxas de prevalência para os negros nos primeiros grupos etários (Figura 14).

\section{Comparações das condições referidas no Brasil e nos Estados Unidos da América por sexo, raça e grupo etário - hipertensão}

As taxas de prevalência de hipertensão, ainda que crescentes para ambos os países em todas as desagregações estudadas diferem numa característica: a concavidade. Para o Brasil, as curvas são convexas, indicando que, com o aumento da idade, diminuem as diferenças entre os grupos etários. As taxas americanas são convexas, isto é, as diferenças entre grupos etários contíguos aumentam para as idades mais avançadas. No Brasil, as taxas femininas são sempre superiores às masculinas. Nos EUA, nas primeiras idades, as taxas se entrelaçam e somente a partir de 45 anos as taxas masculinas superam, ligeiramente, as femininas. As taxas americanas são superiores às brasileiras nas primeiras idades, enquanto estas superam aquelas nas médias e altas idades.

Nas desagregações por raça, nota-se que, entre a população brasileira, os negros apresentam uma maior prevalência de hipertensão, principalmente no que concerne às mulheres. Não há um padrão consistente na população americana. 
Figura 11

Prevalência de artrite e reumatismo.

\section{Figura 11a}

Brasil e EUA - por sexo e grupo etário

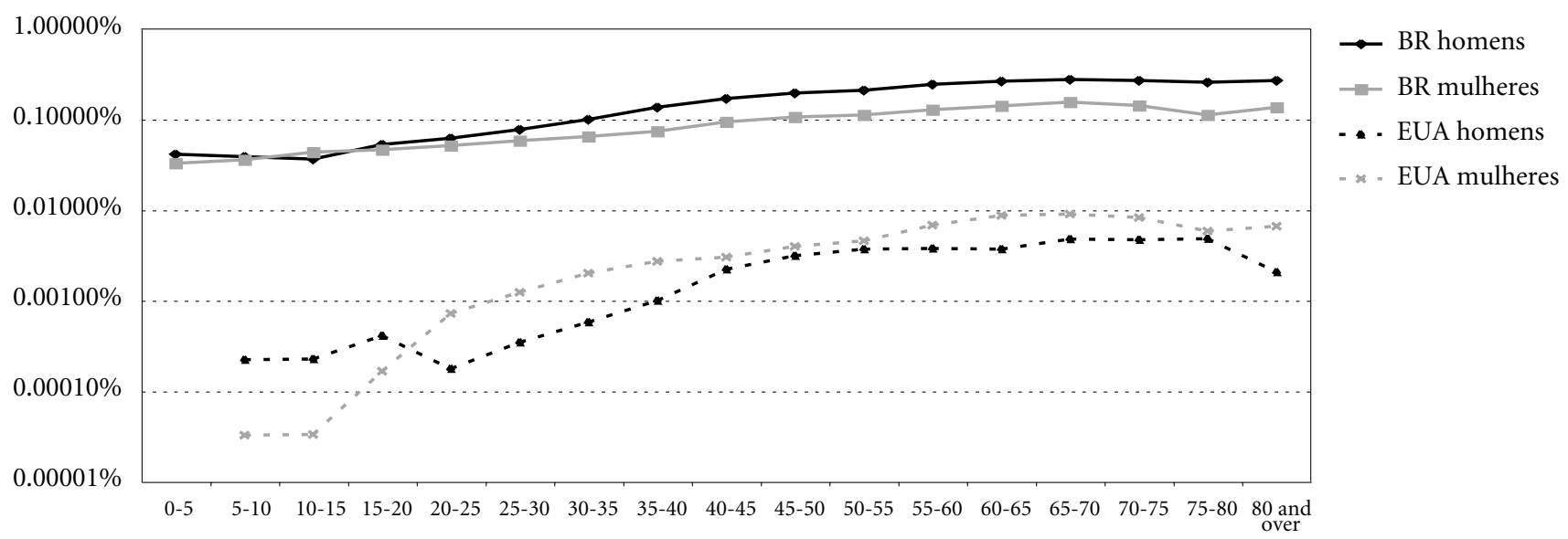

\section{Figura 11b}

Brasil e EUA - por raça/cor e grupo etário

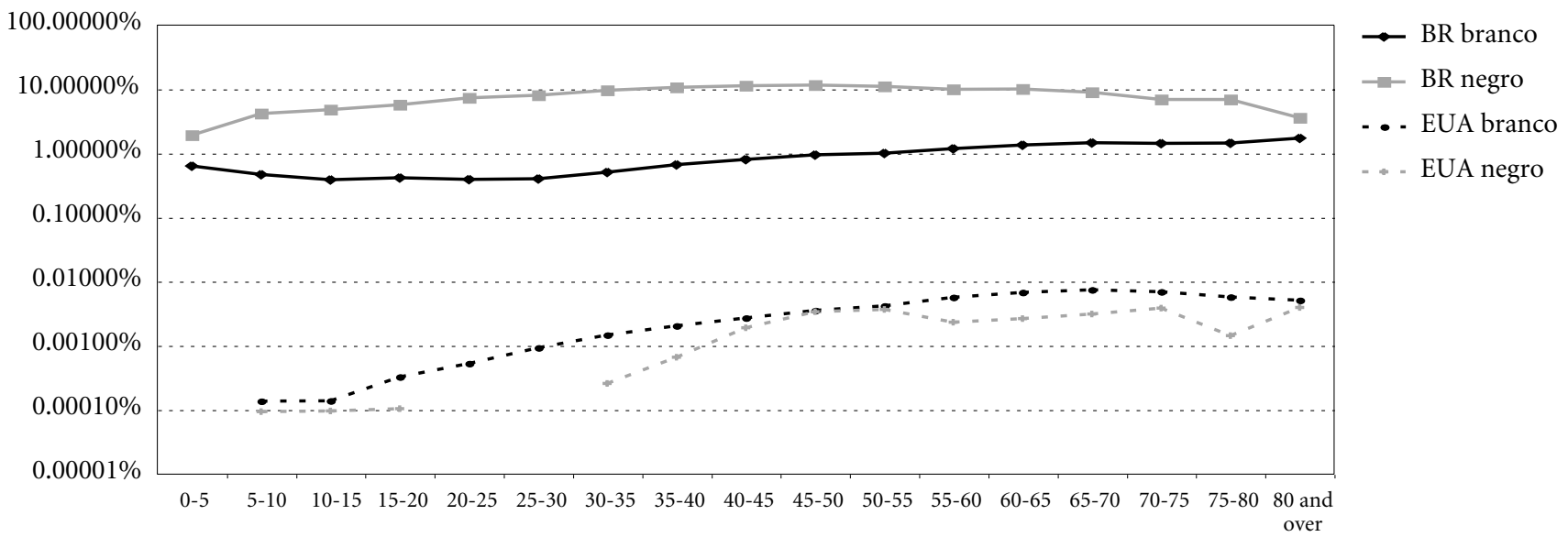




\section{Figura 11c}

Brasil e EUA - Homens - por raça/cor e grupo etário

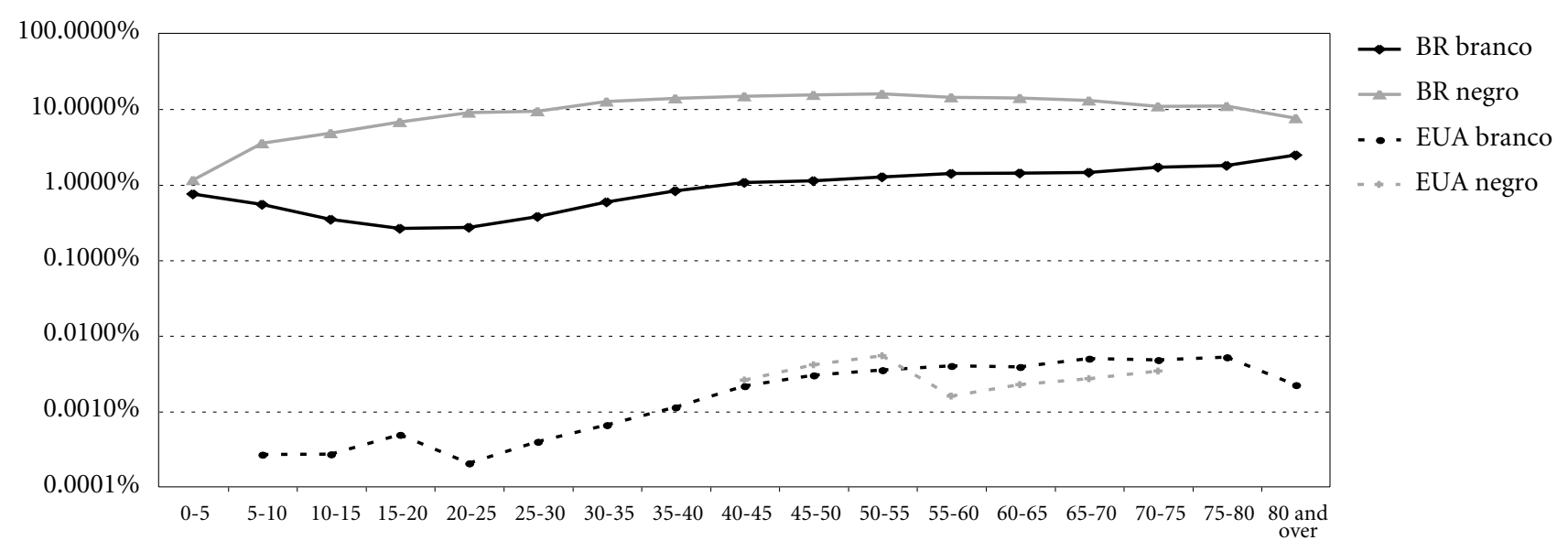

\section{Figura 11d}

Brasil e EUA - Mulheres - por raça/cor e grupo etário

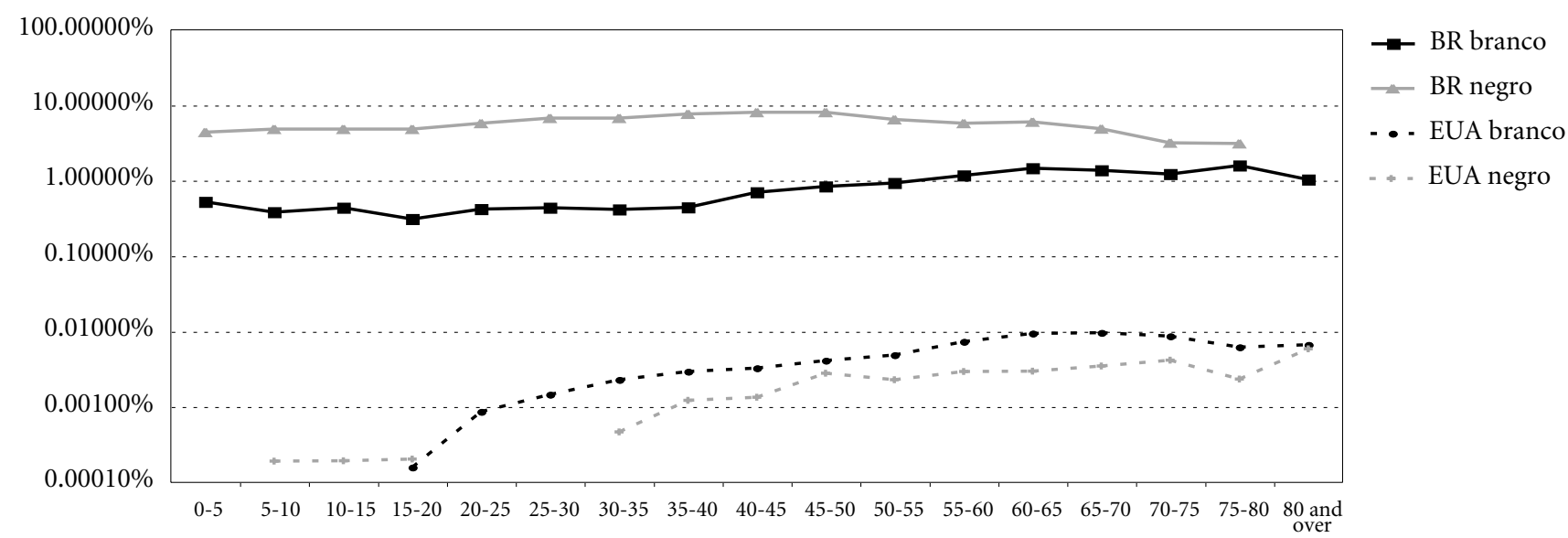


Figura 12

Prevalência de diabetes.

Figura 12a

Brasil e EUA - por sexo e grupo etário

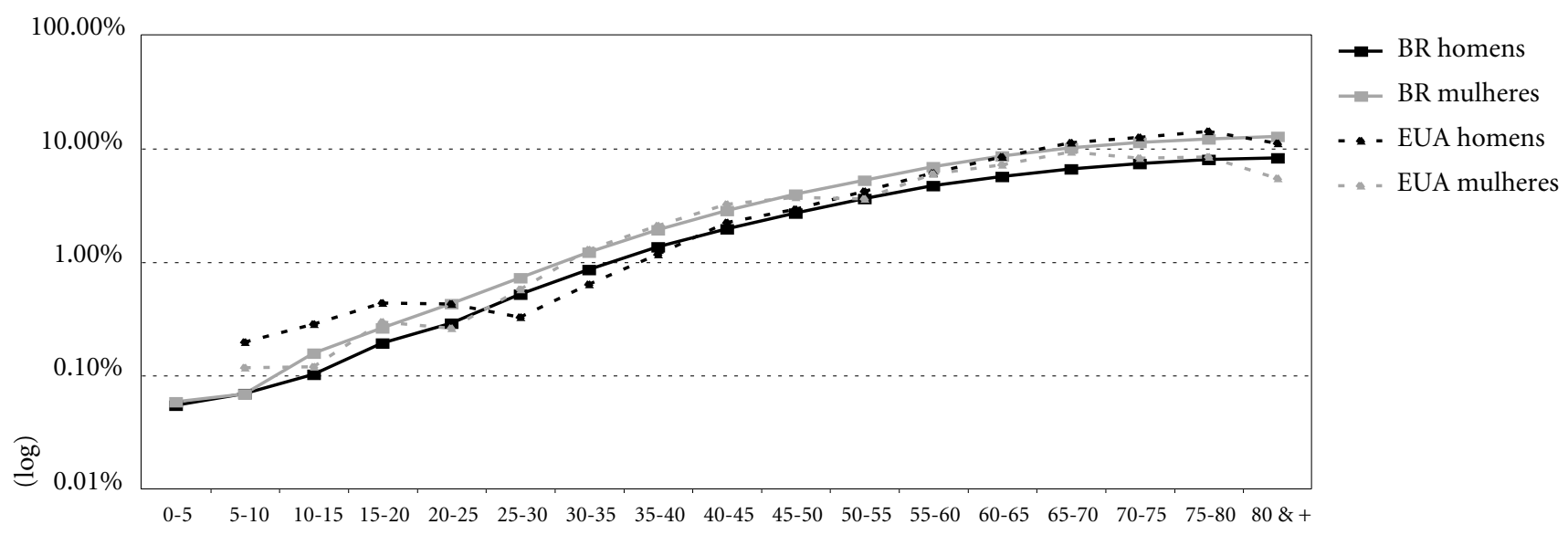

Figura 12b

Brasil e EUA - por raça/cor e grupo etário

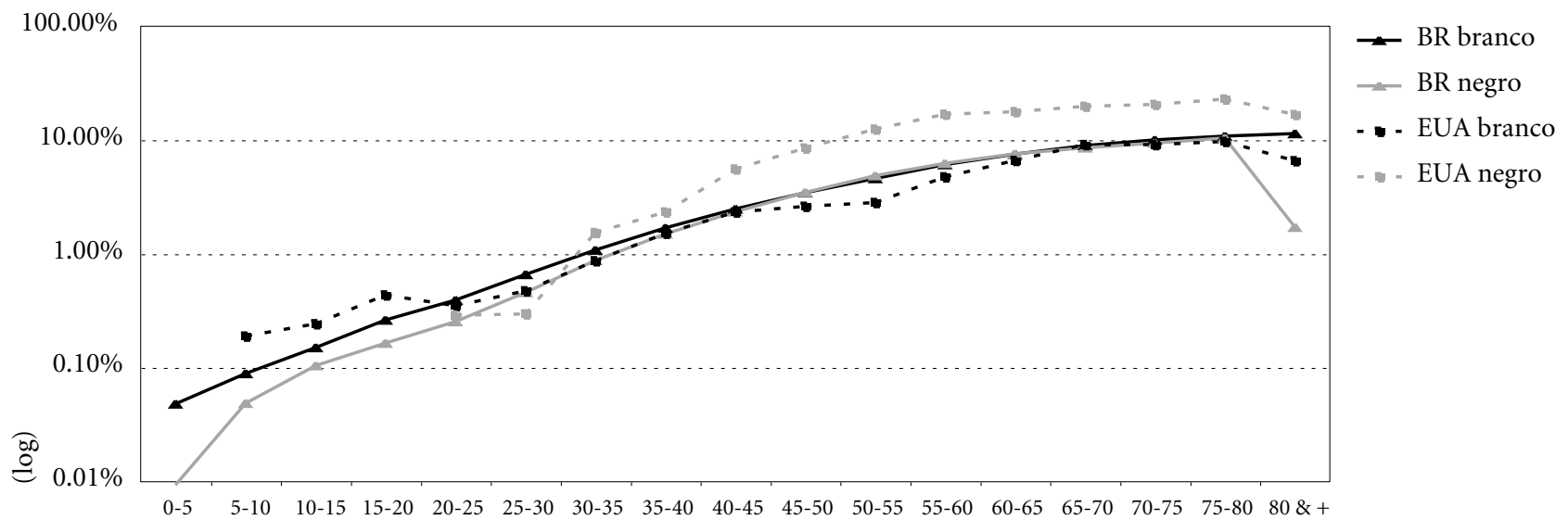

Fonte: PNAD 1998 e NHIS 1996 


\section{Figura 12c}

Brasil e EUA - Homens - por raça/cor e grupo etário

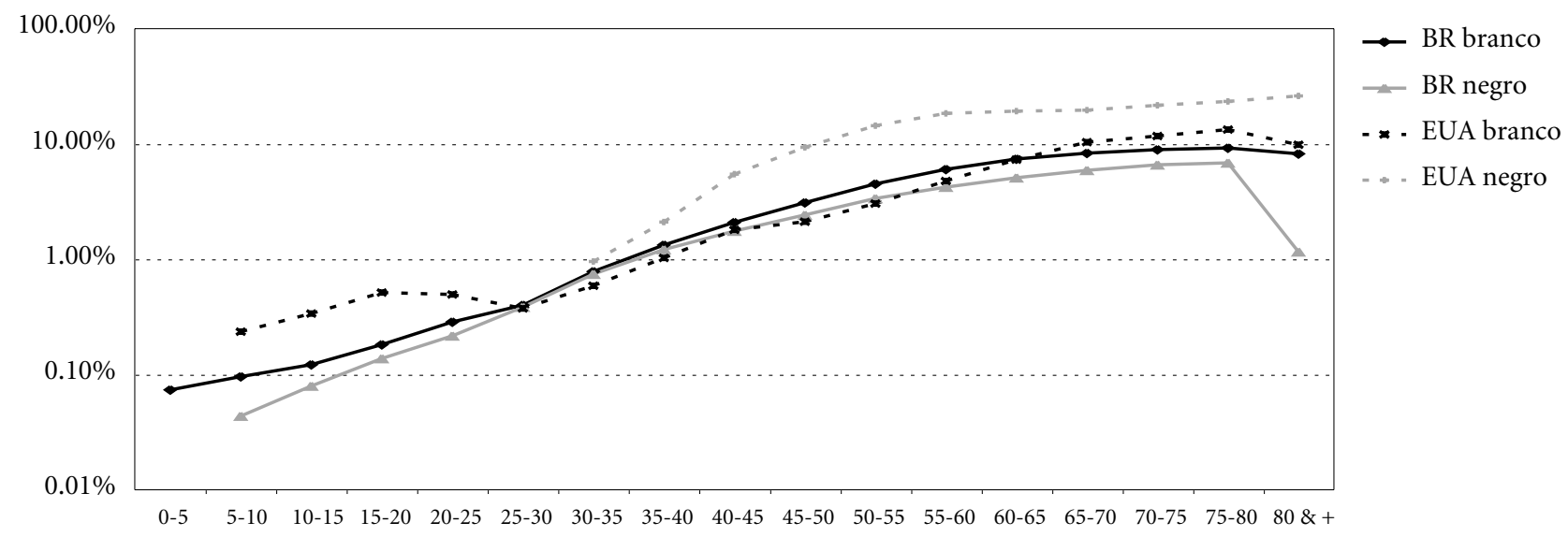

\section{Figura 12d}

Brasil e EUA - Mulheres - por raça/cor e grupo etário

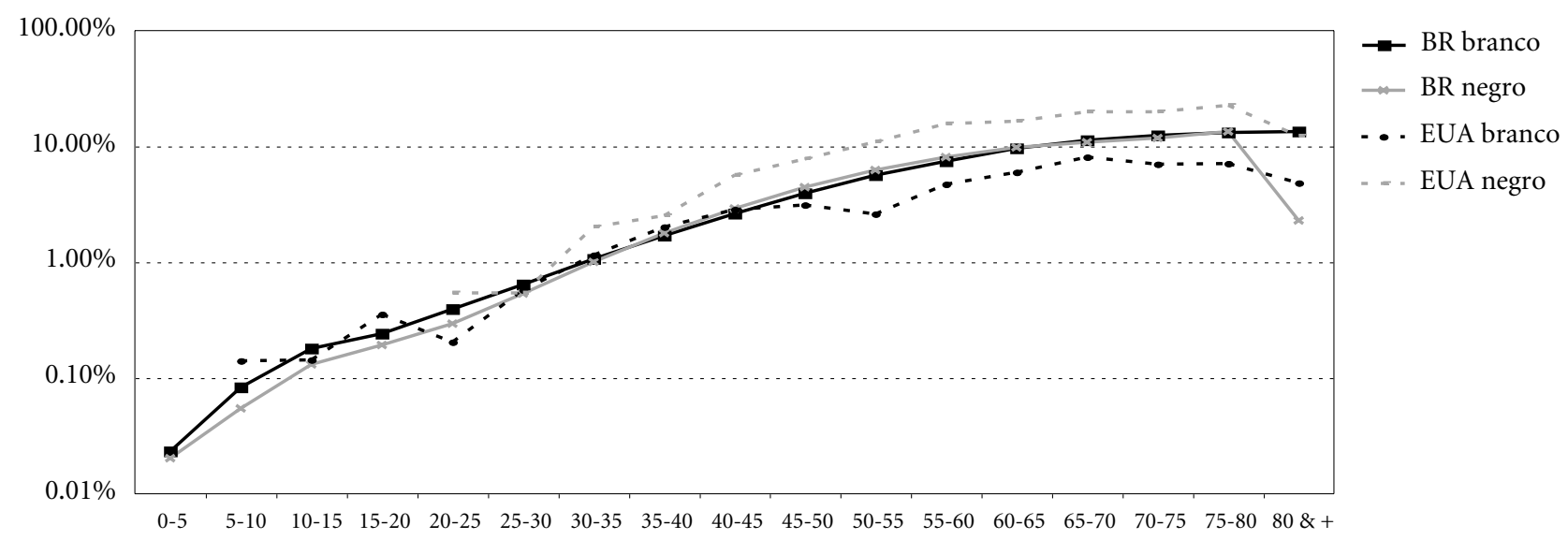


Figura 13

Prevalência de bronquite.

Figura 13a

Brasil e EUA - por sexo e grupo etário

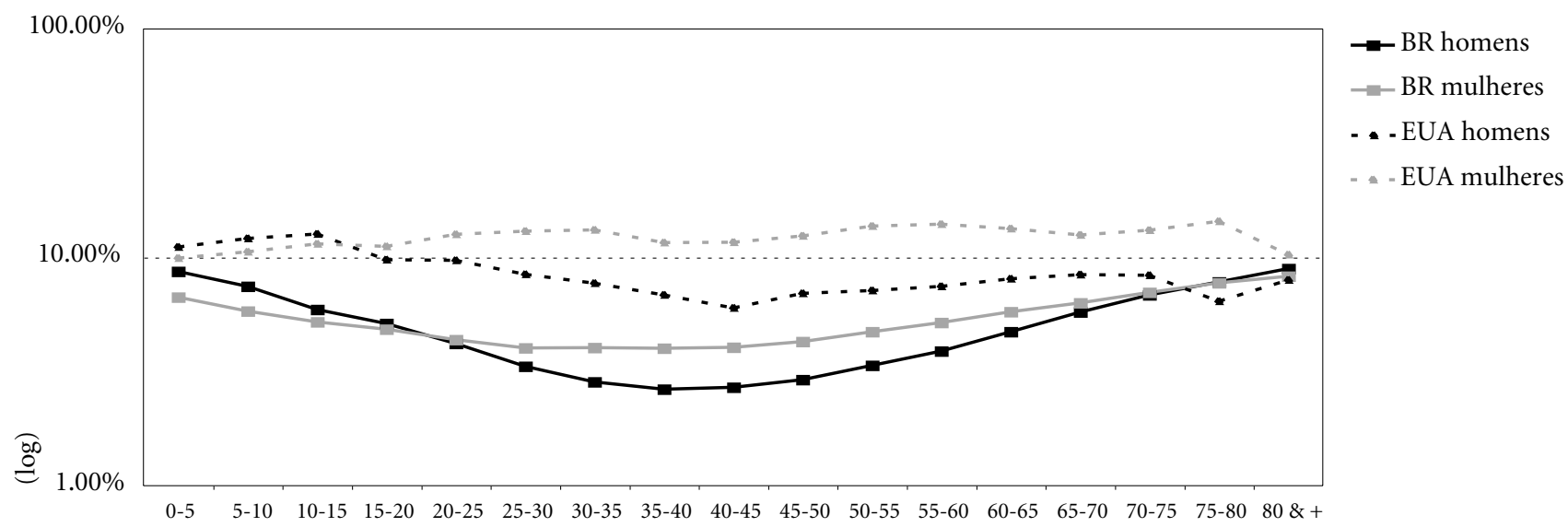

Figura 13b

Brasil e EUA - por raça/cor e grupo etário

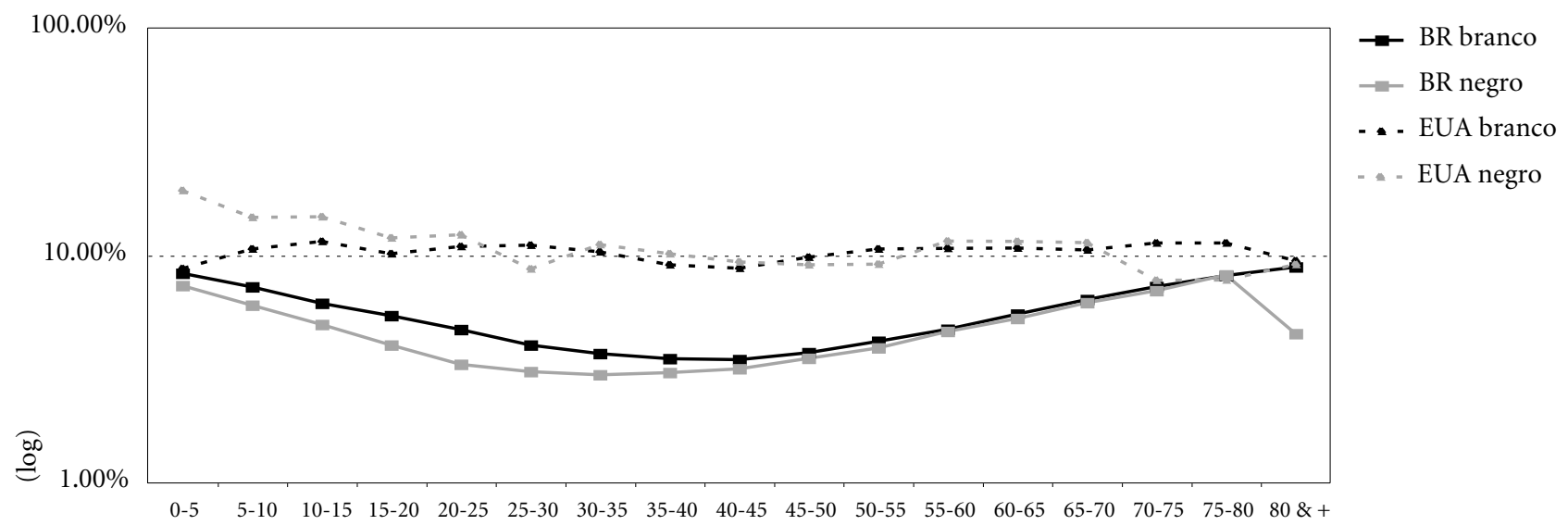


Figura 13c

Brasil e EUA - Homens - por raça/cor e grupo etário

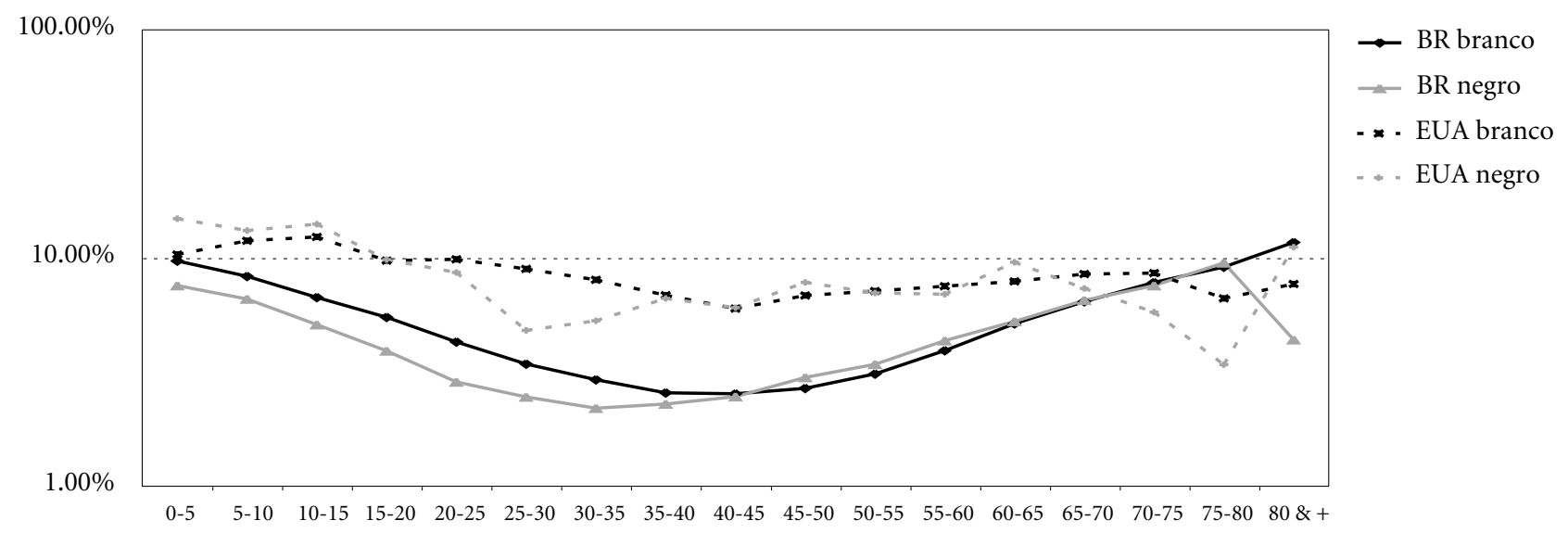

\section{Figura 13d}

Brasil e EUA - Mulheres - por raça/cor e grupo etário

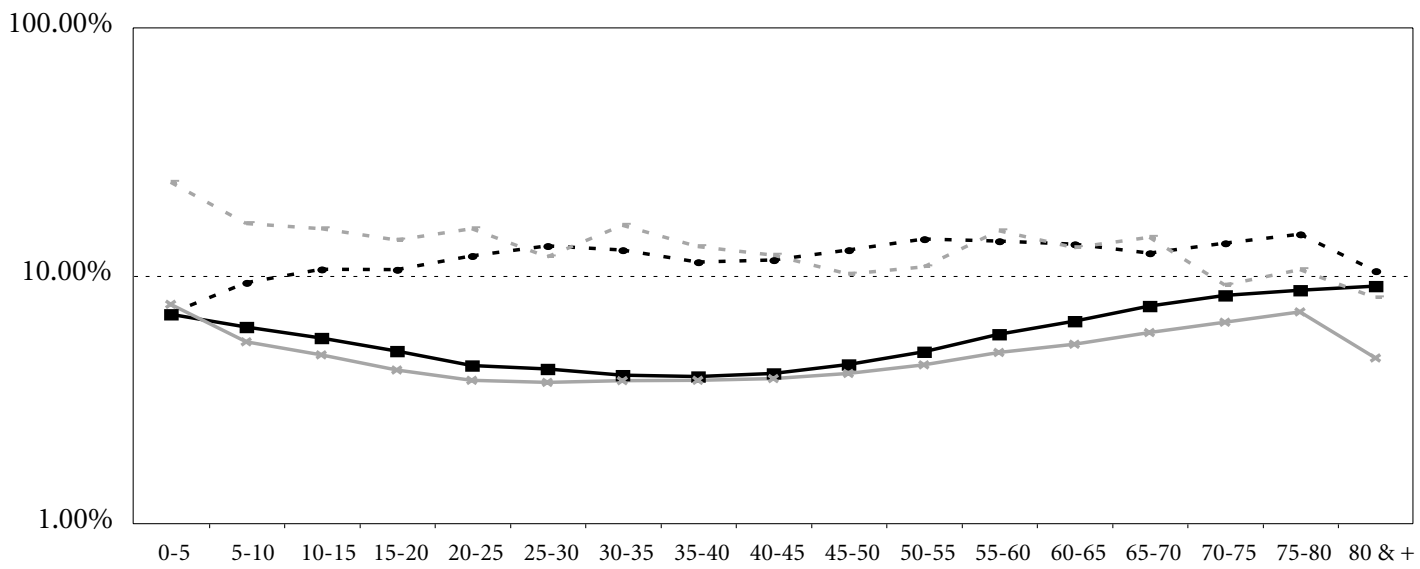

$\rightarrow$ BR branco

$\simeq$ BR negro

-. EUA branco

-.. EUA negro 
Figura 14a

Brasil e EUA - por sexo e grupo etário

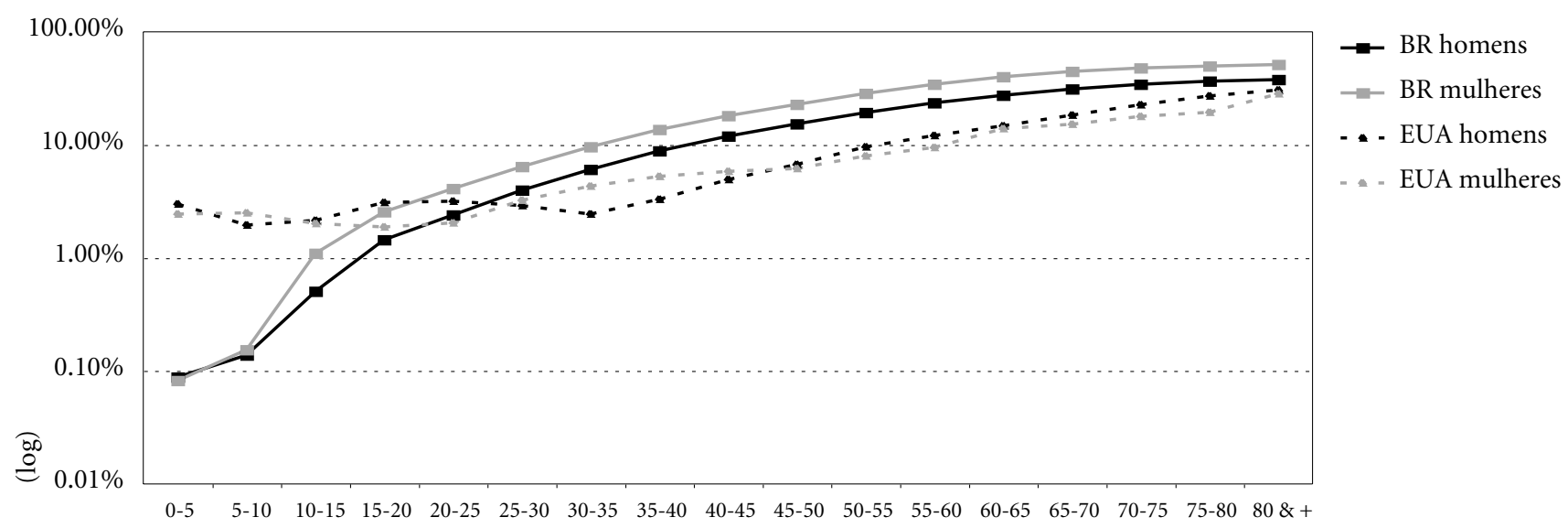

\section{Figura 14b}

Brasil e EUA - por raça/cor e grupo etário

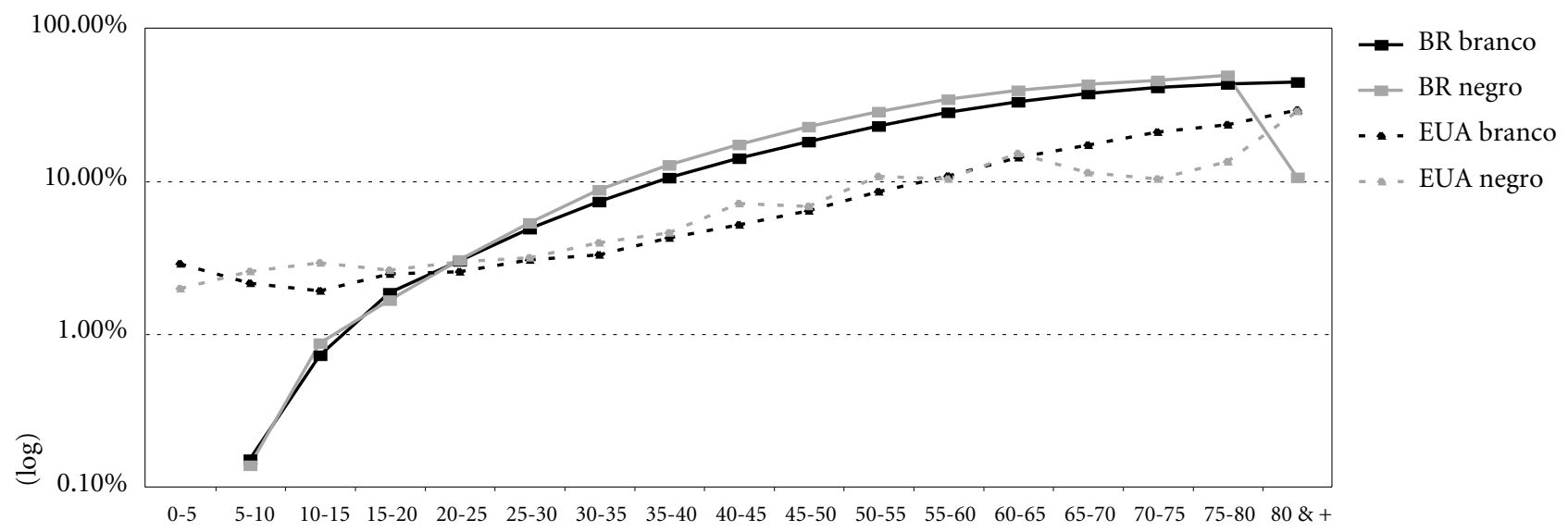


Figura 14c

Brasil e EUA - Homens - por raça/cor e grupo etário

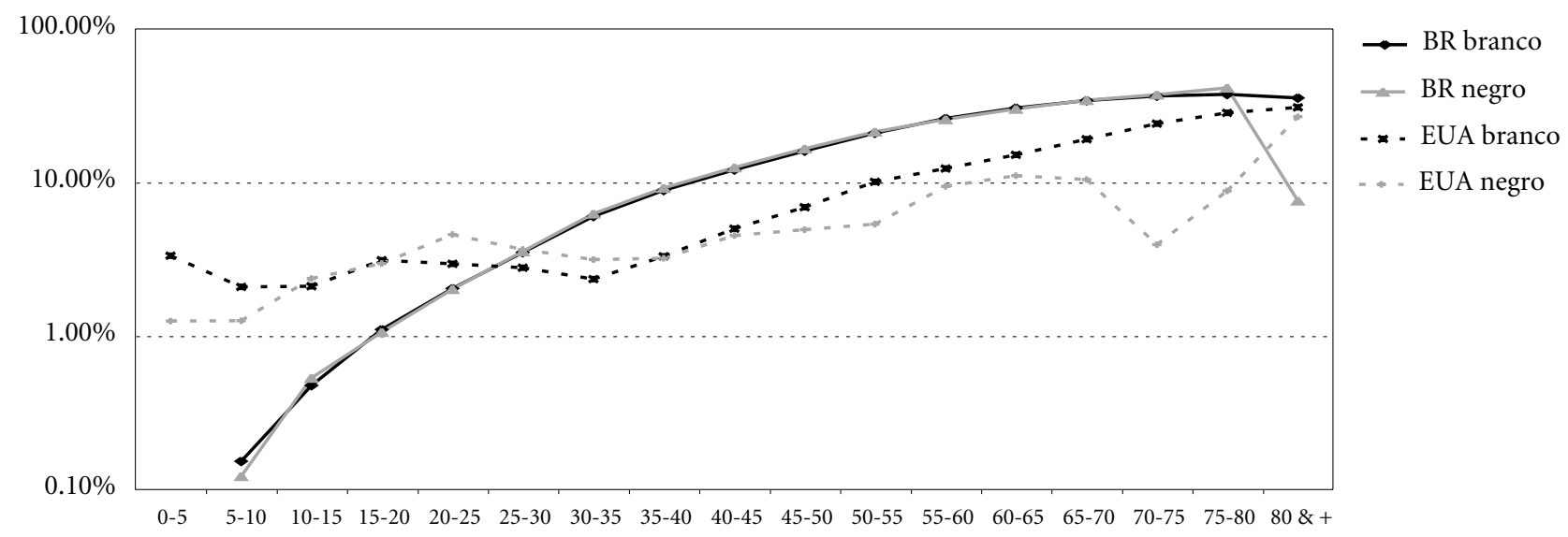

\section{Figura 14d}

Brasil e EUA - Mulheres - por raça/cor e grupo etário

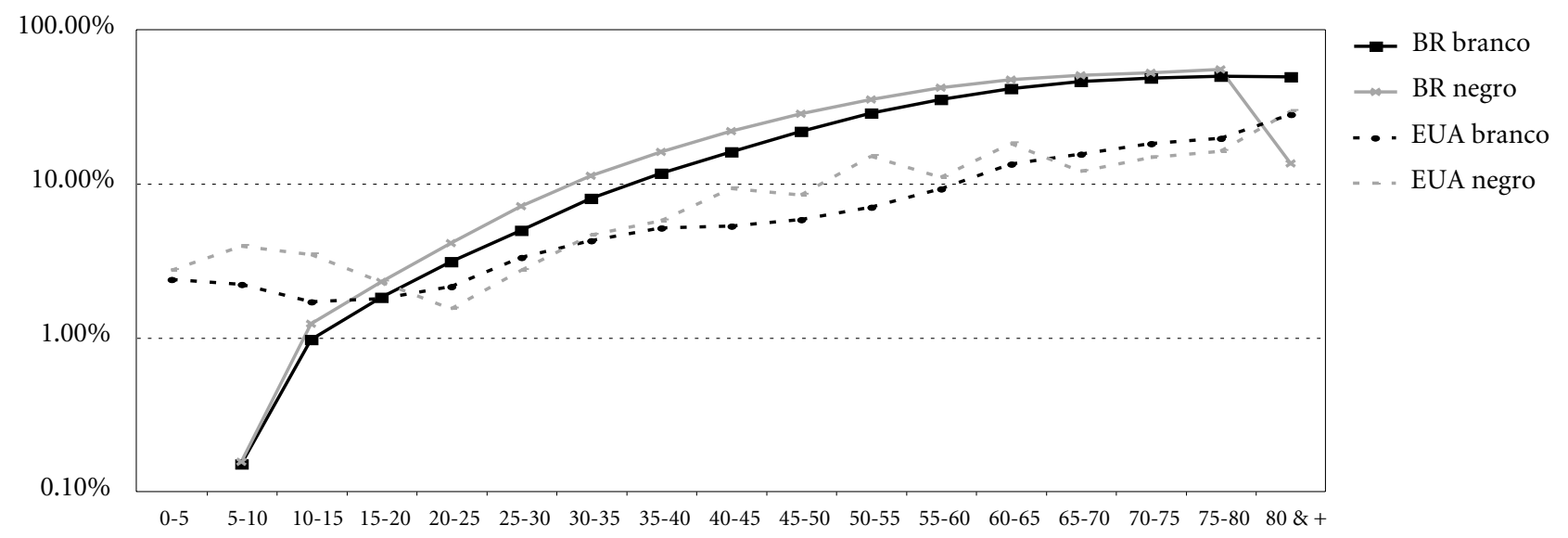




\section{Comparações das condições referidas no Brasil e nos Estados Unidos da América por sexo, raça e grupo etário - doenças do coração}

Em linhas gerais, as taxas de prevalência de doenças do coração apresentam-se como curvas crescentes: para o Brasil, como convexas, para os EUA, com mudança de concavidade, ou seja, côncava/convexa. Na desagregação por sexo (Figura 15), vemos que as mulheres brasileiras apresentam maiores taxas do que os homens a partir de 15 anos de idade. Nos EUA, a situação é o reverso para as idades mais avançadas: para os grupos etários acima de 45 anos, os homens é que declaram maiores taxas de prevalência de doenças do coração. Nas idades mais jovens, é maior a diferença entre as taxas americanas e as brasileiras. Para as mulheres acima de 45 anos, não parece haver uma diferença estatisticamente significativa entre as populações dos dois países.

Como características mais marcantes das curvas referentes à população brasileira desagregada por raça, pode-se dizer que os negros apresentam menores taxas para as idades extremas e maiores para as idades intermediárias. Com respeito à população americana, parece não haver uma diferença significativa entre as mulheres brancas e negras, ao passo que, para os homens a partir dos 35 anos de idade, a taxa dos indivíduos negros é menor do que a dos brancos.

\section{Comentários e conclusões}

As condições gerais de saúde referidas no Brasil são piores do que as declaradas nos EUA, qualquer que seja o critério escolhido, tradução literal ou equivalência de classes. Além disso, as taxas de deterioração dessas condições são maiores entre os brasileiros do que entre os americanos. Na maior parte dos grupos etários, as mulheres registram piores condições de saúde que os homens. Isso é válido para ambos os países e ambas as raças consideradas. As exceções referem-se às idades extremas, os muito jovens e os muito idosos.

Com exceção da artrite e do reumatismo, que se apresentam com valores muito mais altos no Brasil, em geral as morbidades em estudo apresentam taxas de prevalência com valores de mesma ordem de grandeza nos dois países. Usualmente as taxas apresentam a mesma monotonicidade (crescentes, decrescentes ou nenhuma das duas), ainda que com concavidades diferentes (côncava, convexa, plana ou com reversão de concavidade). Parece haver um hiato razoável entre os sexos e raças para quase todas as condições estudadas, tanto no Brasil, quanto nos EUA. O que parece ser interessante é que nem sempre as diferenças de sexo ou raça têm o mesmo sinal para a população do Brasil e dos EUA. 
Figura 15

Prevalência de doenças do coração.

Figura 15a

Brasil e EUA - por sexo e grupo etário

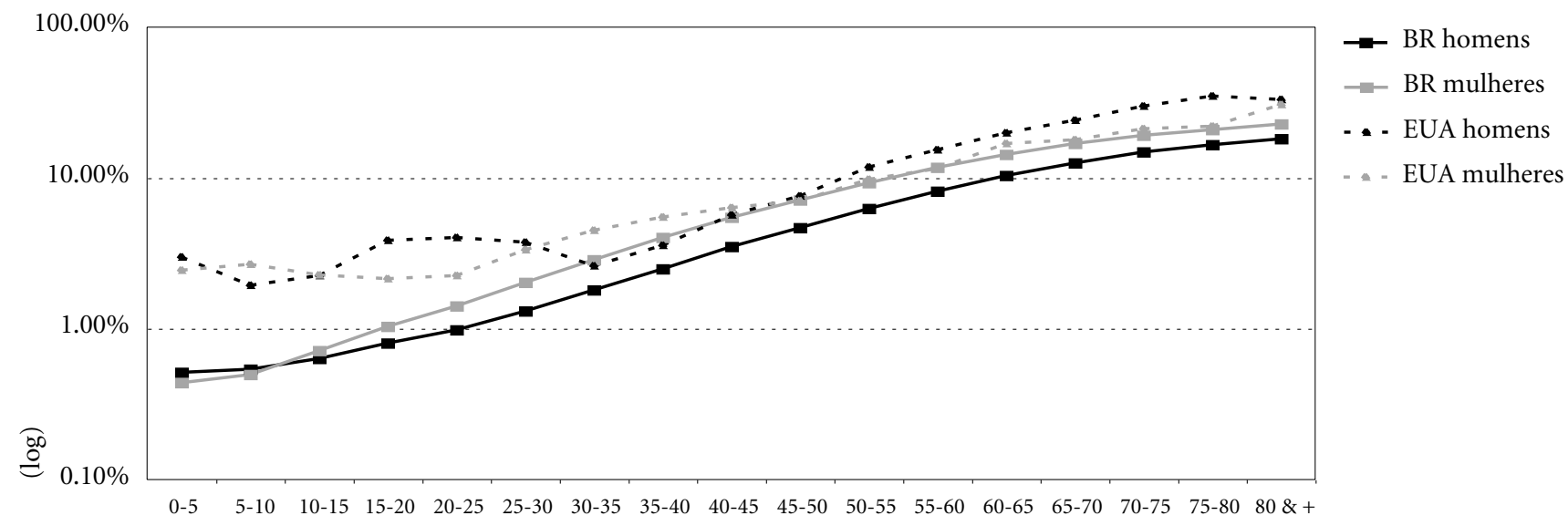

\section{Figura 15b}

Brasil e EUA - por raça/cor e grupo etário

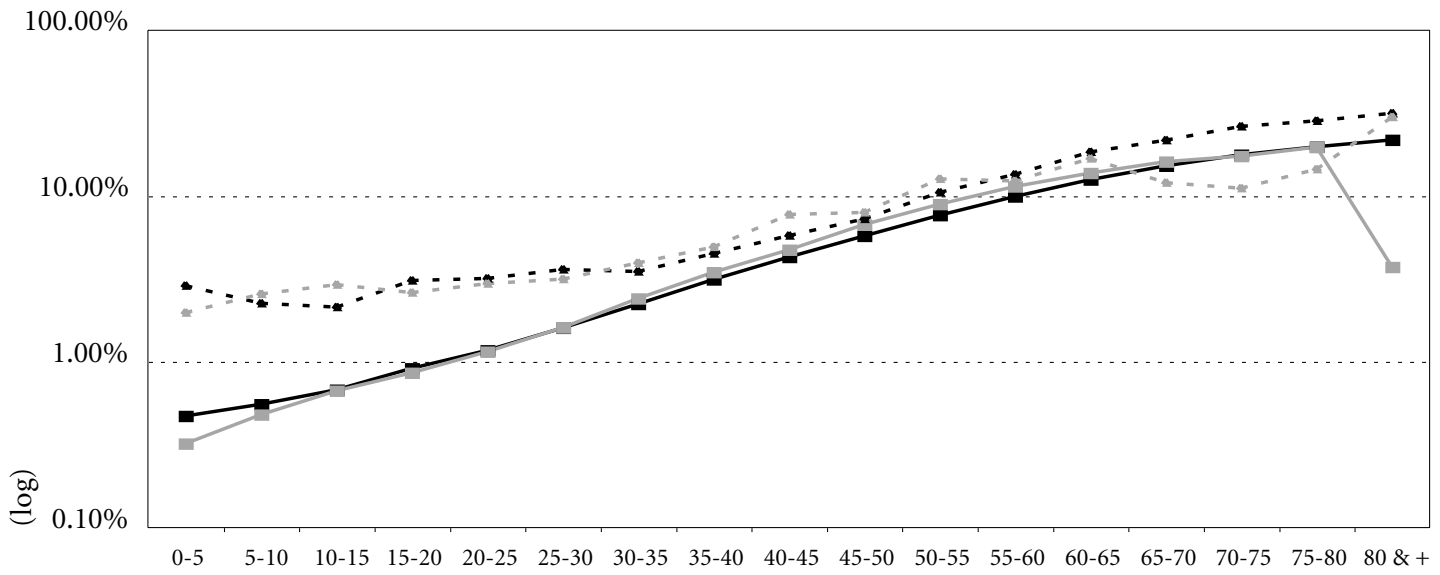

$$
\begin{aligned}
& \text { - BR negro } \\
& \ldots \text { - EUA branco } \\
& \text { - - EUA negro }
\end{aligned}
$$


Figura 15c

Brasil e EUA - Homens - por raça/cor e grupo etário

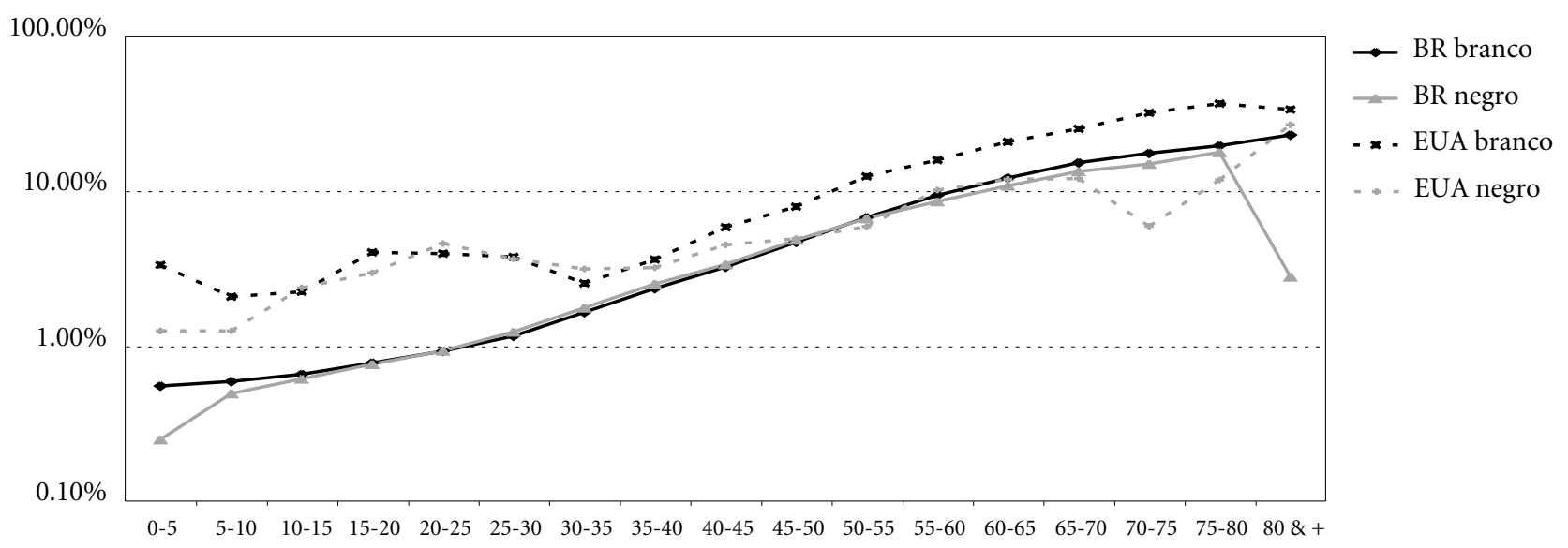

Figura 15d

Brasil e EUA - Mulheres - por raça/cor e grupo etário

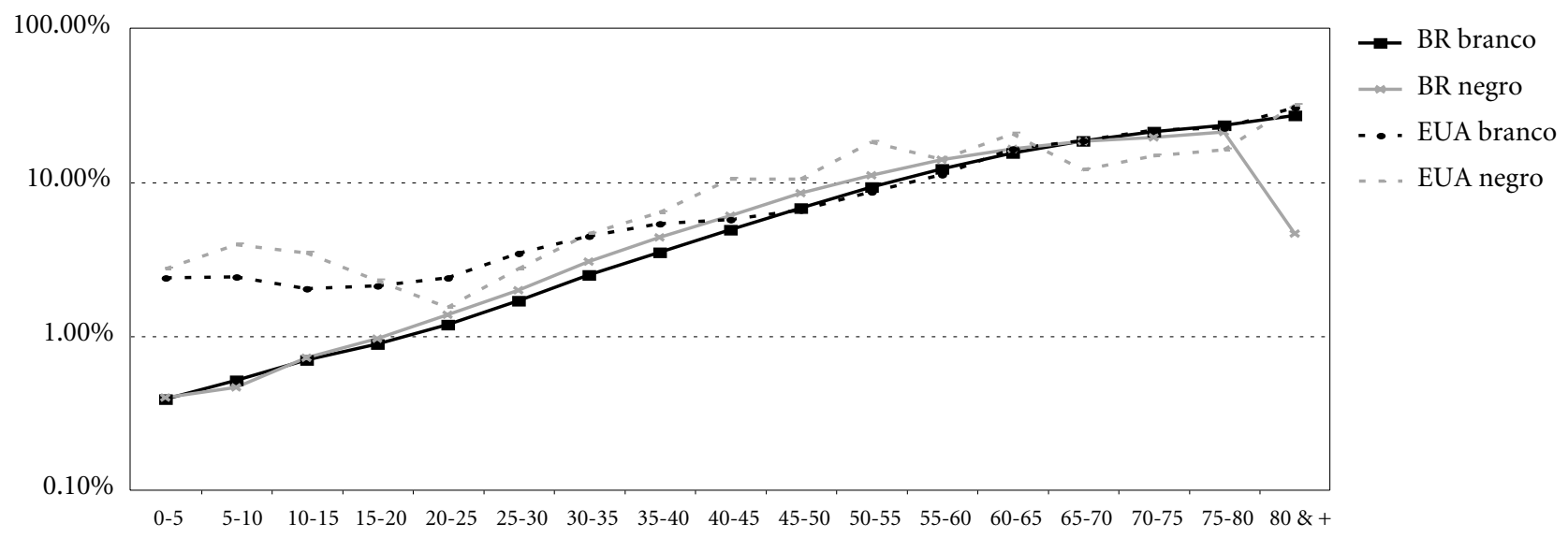

Fonte: PNAD 1998 e NHIS 1996 


\section{Referências bibliográficas}

Costa TCNA 1974. O princípio classificatório 'cor', sua complexidade e implicações para um estudo censitário. Revista Brasileira de Geografia 36(3):91-106

Deb P \& Trivedi PK 1997. Demand for medical care by the elderly: a finite mixture approach. Journal of Applied Econometrics 12:313-326.

Hasenbalg CA 1979. Discriminação e desigualdades raciais no Brasil. Graal, Rio de Janeiro.

Hasenbalg CA \& Silva NV 1991. Raça e oportunidades educacionais no Brasil. In Lovell PA. Desigualdade racial no Brasil contemporâneo. UFMG/Cedeplar, Belo Horizonte.

NHIS 1996. Microdados. NCHS, EUA.

NCHS 1996. Vital and health statistics, current estimates from the NHIS.

Oliveira JS 2001. "Brasil mostra a tua cara": imagens da população brasileira nos censos demográficos de 1872 a 2000. Rio de Janeiro, mimeo.

PNAD 1998. Microdados. IBGE, Rio de Janeiro.

Ries P 1990. Americans assess their health: United States, 1987. Vital and Health Statistics Series 10, n. 174.

Artigo apresentado em 8/8/2002

Aprovado em 25/9/2002

Versão final apresentada em 10/10/2002 